\title{
SIMULATION OF MATHEMATICAL MODEL FOR MONORAIL SUSPENSION SYSTEM UNDER DIFFERENT TRACK CONDITIONS
}

\author{
(Date received: $30.10 .2018 /$ Date accepted: 13.05 .2019$)$ \\ Wafi A. Mabrouk and M. F. L. Abdullah* \\ Faculty of Electrical and Electronic Engineering, Department of Communication Engineering, \\ University Tun Hussein Onn, Malaysia. \\ *Corresponding Author: faiz@uthm.edu.my
}

\section{ABSTRACT}

\begin{abstract}
Designing a new monorail suspension system for an existing monorail bogie to accommodate larger cars, locomotives and more passengers is a difficult and complicated problem to solve. This paper introduces a simulation of a mathematical model for a monorail suspension system that can be used as an analytical tool to investigate and predict the behavior of the model under different speeds and track conditions. In this paper, the simulation is performed to predict some dynamic characteristics monorail suspension system. This research work concentrates on the simulation of 15 degrees of freedom full-car Monorail suspension system. The model features the Monorail body, Front bogie, and rear bogie geometries, adopted equations of motion of the monorail suspension system and system matrices. Numerical Central Difference method was used to obtain the system responses subject to sinusoidal Track excitations. Three Track scenarios that have different loads and different driving speeds were conducted to investigate the monorail suspension system. The system results are analysed in terms of their dynamic responses. Fourier Fast transforms was used to calculate the frequency ranges of dynamic responses. As a result, some very important characteristics of the Monorail suspension system were revealed, with indicators that help to understand the effects of driving speeds and different loads, which can be used to better understand the system dynamic performance, to improve Monorail suspension system designs flaws detection.
\end{abstract}

Keywords: Monorail-train, MDOF Suspension System Model, Suspension System Dynamic Response, Track Surface Excitation, Vibration

\subsection{INTRODUCTION}

Nowadays, there is an increased demand for public transportation systems, especially in megacities. This increased transportation demand, pushed transportation authorities and manufacturers to plan new projects and expand existing monorail systems to accommodate the increased demand. This required engineers to develop and design larger monorail systems with more powerful locomotives and new dimensions to accommodate more passengers, therefore new suspension system designs are needed in order to overcome new design problems.

Vehicle dynamics of multi-body systems is a relatively newly established discipline that is essential in handling multibody systems design problems based on classical and modern mechanics. It was established from various ride problems experienced during the last 100 years, where engineers such as Gilchrist et al., [1] began to analyse the dynamic response of two-axle vehicles to better understand the ride dynamics and handling dynamics of trains. Before that, in 1950's equations of motion were formulated to examine the characteristics of rigid body locomotives, such as stability on curves. It helped understanding stability at that time. However, it would be carried out analytically and the solution to the equations of motion for an MDOF (Multi Degrees of Freedom) system created a problem that if attempted would be time-consuming and error-prone, due to the lack of computational power of analog computers back then in the early 1950's[2].

After the 1950's, the interest in numerical methods and computer applications in all engineering fields increased, in order to develop efficient ways of computation libraries and standard routines to solve differential equations and eigenvalue problems. This helped researchers and designers to execute simulations of complex nonlinear models with MDOF. These simulations were constructed based on equations of motion that were formulated manually, then coded into simulation platforms such as MATLAB and ANSYS to solve specific problems such as dynamic response, vibrations, track irregularities and displacements [3]. In 1974 Jenkins et al., analysed the vertical response of a vehicle to a dipped joint, his study is widely cited and has shown the responses that are involved in railways and contact stiffness. He also illustrated distinct peaks of the slower transient of the unsprung mass and track stiffness [3]. The responses of complete models helped in establishing indications to ride quality and passengers comfort assessments. This helped in developing international standards such as ISO263 that sets vibration limits to protect humans, due to their sensitivity to vibrations. [4].

Many transportation systems such as cars, trucks, airplanes had their fair share of research work, in terms of vehicle 


\section{SIMULATION OF MATHEMATICAL MODEL FOR MONORAIL SUSPENSION SYSTEM UNDER DIFFERENT TRACK CONDITIONS}

dynamics studies. The focus on these systems is due to their uses and popularity. However, Monorail trains differ in terms of uses and popularity. Their characteristics can be studied using similar approaches, due to the fact that the system incorporates some of large truck parts, for example, the load wheels. However, the number of work and studies done on Monorail suspension systems is low compared to other transportation systems and it's implemented by a few specialised companies.

H. Claus and W. Schiehlen developed a method for modeling and simulation of railway bogie structural variations to investigate the system dynamics. However, their study was conducted on bogie MD 530 of the German ICE (Intercity-Express) passenger coach. The study pointed out the properties of the bogie in terms of elastic resonances ranges, elastic deformation and static stress distribution of critical parts of the bogie frame [5].

On the other hand, current monorail related research work was focused on the monorail bridges dynamic response, for example, Meysam Naeimi, Meisam Tatari, Amin Esmaeilzadeh and Mohammad Mehrali [6] used finite element method to assess the dynamic behavior of the monorail - bridge interaction system. However, a Monorail vehicle model had to be formulated to achieve the required result. Furthermore, in Japan, C. H. Lee, M. Kawatani, C. W. KIM, N.Nishimura, and Y. Kobayashi [7] conducted similar studies to investigate the dynamic response of monorail-bridges interaction. Besides that, they included ISO 2631 to assess the riding comfort of ridership. They used an idealised MDOF Monorail train model to interact with 6 DOF bridge model. Then later Chul-Woo Kim and Mitsu Kawatani, extended the model to include steel bridges under moderate earthquakes [8].

However, Suspension system plays a mandatory role in the performance of monorail in terms of, riding comfort by isolating track vibrations and movements from passengers and providing good handling of the monorail car in turns and while accelerating or stopping at stations.

\subsection{METHODS}

In this paper, we focus on the modeling and formulation of a multi-Degree of Freedom (DOF) Monorail suspension system, by incorporating body and suspension geometries. We aim to present a tool that analyses and formulate the assumed suspension system model. The analysis describes the coupled motions of monorail bogies and body. The developed model provides equations of motions. Track excitations include simple sinusoidal input, but there is no random input adopted. Piecewise linearization of the real nonlinear shock absorbers is replaced by equivalent conventional linear invariant viscous damping. The mathematical model is derived using Lagrange's equation and Central Difference Method as a numerical solution. The modeling practice developed in this paper incorporates previous modeling techniques [7] [9] [17] [18] [19] and adds some new analysis features that help outline monorail bogies dynamic equations. However, they do not cover all random track excitations and nonlinear spring characteristics.

\subsection{Monorail Train Model}

Generally, there are two types of monorail trains, suspended and straddle type. In this paper Straddle, monorail type is chosen, due to its popularity. A monorail train car sits on two bogies, that are positioned in front and the rear of the car. Each bogie is U-shaped with 3 three sets of wheels, that serve different functions and they are; traveling wheels (or load wheels), steering wheels and stabilizing wheels.

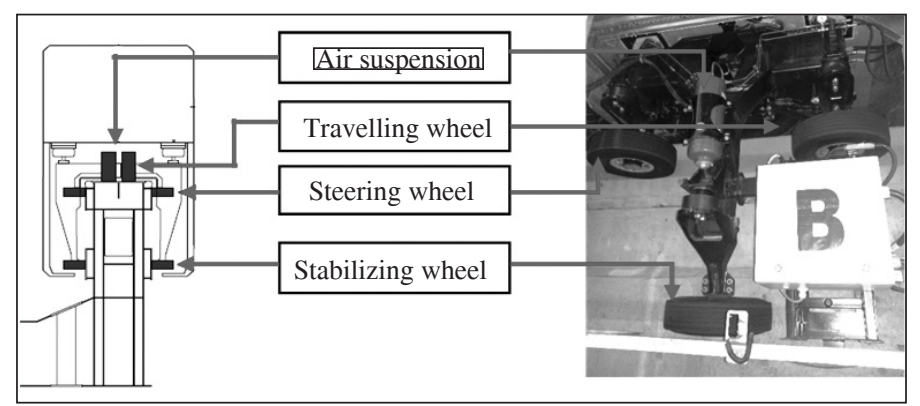

Figure 1: Components of monorail train and it's Configuration

The geometrical properties that are important in modeling the Monorail suspension system are mainly, Monorail bogies dimensions in terms of width, height and length. In addition to monorail body dimensions in the same terms, all adopted properties used in this research are tabulated in Table 1 and Table 2 (See A1). For consistency, C. H. Lee and his fellow researches group [11], model was adopted, since it details the Monorail train model Ideally for the purpose of bridge dynamic analysis investigation. However, in this paper, its solving algorithm is adjusted to serve the purpose of solving the monorail suspension system dynamic response problems.

Based on Monorail Suspension geometrical, static and dynamic properties can be idealized. Monorail model with 15 DOF, that represents a dynamic system. The model is assumed, based on the graphical configuration of the monorail components and the number of wheels. Bogies and monorail geometry are summed together to form a complete model as shown in (Figure 2). In addition, (Table 1) (See A.1) tabulates all the values that are considered in this paper.

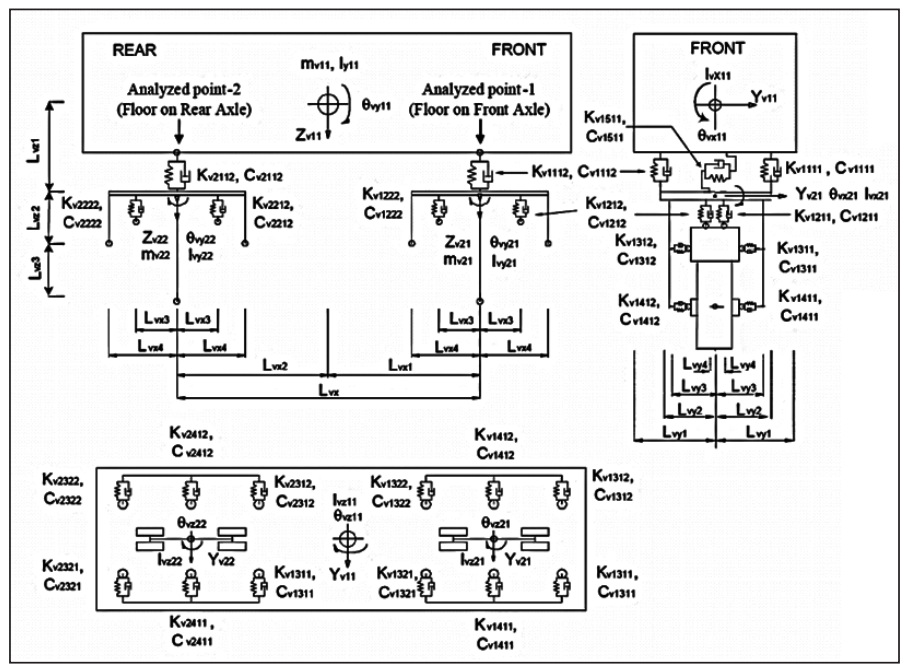

Figure 2: Illustrates an idealized 15DOF Monorail Train Model [11]

Figure 2 Illustrates the monorail model, where $\mathrm{m}, \mathrm{K}$, and $\mathrm{C}$ represent the mass, stiffness and damping coefficients respectively. Besides that, vertical, lateral and rotational motions are indicated by Z, Y, and $\theta$. Furthermore, monorail car is assumed as a rigid body, with the support of a set of springs and dashpots, with linear properties. In addition to maintaining constant contact between the wheels and the rack, 
while neglecting the longitudinal direction variables. Based on Figure 2, there are many notations tabulated to model the train mathematically and further explain the dynamic properties that are related to this research, thus in Table 1 in A1 the train model parameters and their values are summed and used later in the mathematical formulation.

\subsection{Monorail Train EOM (Equations of Motion)}

Monorail train EOM for 15 DOF model, is formulated with the use of energy method, then utilizes Lagrange's EOM in Eq (1). This method is used for its diversity and efficiency in analyzing a dynamic system. [9], [12], [13]. Equation (1) is developed, based on a vehicle on highway bridge energy equations [15], [16].

$$
\frac{\partial}{\partial t}\left(\frac{\partial T}{\partial \dot{a}_{i}}\right)-\frac{\partial T}{\partial a_{i}}+\frac{\partial P}{\partial a_{i}}+\frac{\partial D}{\partial \dot{a}_{i}}=0
$$

Where, $\mathrm{T}$ is Kinetic energy and $\mathrm{P}$ is Potential energy. Furthermore, D is dissipation of energy, ai is a generalised coordinate. Equation (1) is used to partially differentiate the equations of energy and acquire EOM of Monorail suspension system. However, Energy equations are defined below:"

$$
\begin{aligned}
& T=\frac{1}{2} \sum_{v=1}^{n v}\left[m_{v 11} \dot{Z}_{v 11}{ }^{2}+m_{v 11} \dot{\boldsymbol{Y}}_{v 11}{ }^{2}+I_{v x 11} \dot{\theta}_{v x 11}{ }^{2}+I_{v y 11} \dot{\theta}_{v y 11}{ }^{2}+I_{v z 11} \dot{\theta}_{v z 11}{ }^{2}\right. \\
& \left.+\sum_{i=1}^{2}\left\{\boldsymbol{m}_{v 2 i} \dot{\boldsymbol{Z}}_{v 2 i}{ }^{2}+\boldsymbol{m}_{v 2 i} \dot{\boldsymbol{Y}}_{v 2 i}{ }^{2}+\boldsymbol{I}_{v x 2 i} \dot{\boldsymbol{\theta}}_{v x 2 i}{ }^{2}+\boldsymbol{I}_{v y 2 i} \dot{\boldsymbol{\theta}}_{v y 2 i}{ }^{2}+\boldsymbol{I}_{v z 2 i} \dot{\boldsymbol{\theta}}_{v z 2 i}{ }^{2}\right\}\right] \\
& P=\frac{1}{2} \sum_{v=1}^{n v}\left[\sum_{i=1}^{2} \sum_{j=1}^{2} \sum_{n=1}^{2}\left\{\boldsymbol{K}_{v i 1 j n} \boldsymbol{R}_{v i 1 j n}{ }^{2} \boldsymbol{\delta}_{1 j}+\boldsymbol{K}_{v i 2 j n} \boldsymbol{R}_{v i 2 j n}{ }^{2}+\boldsymbol{K}_{v i j j n} \boldsymbol{R}_{v i 3 j n}{ }^{2}+\boldsymbol{K}_{v i 4 j n} \boldsymbol{R}_{v i 4 j n}{ }^{2} \delta_{1 j}\right\}\right. \\
& \left.+\sum_{i=1}^{2} \boldsymbol{K}_{v i 511} \boldsymbol{R}_{v i 511}^{2}\right]
\end{aligned}
$$

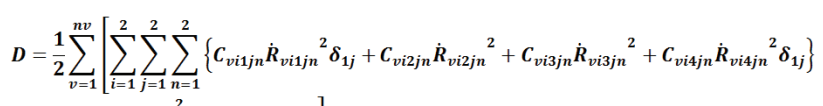

$$
\begin{aligned}
& \left.+\sum_{i=1}^{2} C_{v i 511} \dot{R}_{v i 511}{ }^{2}\right]
\end{aligned}
$$

Where, nv is the number of cars in a monorail train, I the mass moment of inertia and $v$ the number of cars on the bridge. Additionally, components of train cars are indexed using $i$ as an indicator of suspension position of a car and $i=1$ and 2 to depict the front and rear suspensions. Besides, $\mathrm{j}$ is used to indicate the tire position in a bogie, where $\mathrm{j}=1$ and 2 are the front and rear tires of the bogie system, respectively. To indicate left and right sides of the care $\mathrm{n}$ is used, while Rvimjn depicts the relative displacement at springs and dampers. $\delta_{\mathrm{ij}}$ is Kronecker's delta, where $\delta i j=1$ for $i=j$ and $\delta i j=0$ for $i \neq j$. Finally, the property of front suspension is indicated by $\delta 1 \mathrm{j}$. [8]

After formulating the energy equations, relative displacements of the monorail car are formulated below:"

$$
\begin{aligned}
& \boldsymbol{R}_{v i 1 j n}=Z_{v 11}-Z_{v 2 i}+(-1)^{n} \theta_{v x 11} L_{v y 2}-(-1)^{n} \theta_{v x 21} L_{v y 2}-(-1)^{i} \theta_{v y 11} L_{v x i} \\
& \boldsymbol{R}_{v i 2 j n}=Z_{v 2 i}-(-1)^{j} \boldsymbol{\theta}_{v y 2 i} L_{v x 3}+(-1)^{n} \boldsymbol{\theta}_{v x 2 i} L_{v y 4} \\
& \boldsymbol{R}_{v i 3 j n}=Y_{v 2 i}+(-1)^{j} \boldsymbol{\theta}_{v z 2 i} L_{v x 4} \\
& \boldsymbol{R}_{v i 4 j n}=Y_{v 2 i}+\boldsymbol{\theta}_{v x 2 i} L_{v z 3} \\
& R_{v i 5 j n}=Y_{v 11}-Y_{v 2 i}-\theta_{v x 11} L_{v z 1}+(-1)^{i} \theta_{v z 11} L_{v x i}
\end{aligned}
$$

Where,

Zvij: Vertical displacements of front and rear suspension system.

Yvij: Lateral displacements of front and rear suspension system.

Lvx, Lvy, Lvz: The monorail car geometry in $\mathrm{x}, \mathrm{y}$ and $\mathrm{z}$-axis respectively

$\theta \mathbf{v x}, \theta \mathbf{v y}, \theta \mathbf{v z}$ : The Rolling, Pitching and yawing of the monorail body respectively "[8]

Since equations of energy and displacement of monorail body are defined and ready. Therefore to acquire motion equations of the monorail system with $15 \mathrm{DOF}$, the equations need to be further formulated by defining the bouncing, axle hop, lateral translations, Bogie Sway, Rolling, Pitching, Yawing, and bogie Windup. Then, in order to calculate more efficiently, Guyan reduction methods are utilised and equations are simplified [14]. For the monorail track, traveling wheels, steering wheels and stabilising wheels loads have an effect on the track that can be calculated. However, it is neglected in this paper, where the focus is on the suspension system. Throughout the modeling Guyan simplification procedure is used. Displacements are classified into master and slave DOF, where monorail car displacements rely on front and rear bogies motions. Thus, master DOF are assumed for the monorail car and slave DOF are assumed for each bogie individually [6].

The constructed monorail 15 DOF model from Figure2 and track excitations define the equations of motion of monorail model and describe both systems interaction later on. Based on the adopted methods, forced track excitations for a monorail train are defined as:

$M \ddot{x}+C \dot{x}+K x=f(t)$

Where, $\mathbf{M}=$ Mass matrix $\quad \mathbf{C}=$ Damping matrix

\section{$\mathbf{K}=$ Stiffness matrix $\quad \mathbf{f}(\mathbf{t})=$ Track sinusoidal excitations}

\section{$\ddot{\mathbf{x}}=$ Acceleration $\quad \dot{\mathbf{x}}=$ Velocity $\quad \mathbf{x}=$ Generalized displacement}

Moreover, formulas below are the monorail track wheel loads, based on driving wheel, steering wheel and stabilising wheel [7]:

$$
\begin{aligned}
& P_{v i 2 j n}=\frac{g}{4}\left\{m_{v 11}\left(1-L_{v x i} / L_{v x}\right)+m_{v 2 i}\right\}+K_{v i 2 j n} R_{v i 2 j n}+C_{v i 2 j n} \dot{R}_{v i 2 j n} \\
& P_{v i 3 j n}=K_{v i 3 j n} R_{v i 3 j n}+C_{v i 3 j n} R_{v i 3 j n} \\
& P_{v i 4 j n}=K_{v i 41 n} R_{v i 41 j n}+C_{v i 41 j n} \dot{R}_{v i 41 j n}
\end{aligned}
$$

Where, $\mathrm{P}_{\text {vi } 2 \text { jn }}$ is the driving wheel load, $\mathrm{P}_{\mathrm{vi} 3 \mathrm{jn}}$ steering wheel load and $\mathrm{P}_{\mathrm{vi} 4 j \mathrm{n}}$ is stabilising wheel load.

\subsection{Track Surface Excitation Matrix}

Track surface excitation matrix is defined in this section, where the monorail suspension system response can be later solved [18] under defined excitations. In this case, the motions of wheels correspond to the Track beam surface excitations, which in return impose harmonic vibrations that the 15 DOF model 
respond to accordingly. Thus, by letting the track surface profile excitations, applied to the wheels, with sinusoidal inputs the following equation can be obtained:-

$e x_{1}=A_{t} \sin \left(\omega_{d r} t+\varphi_{1}\right)$

$e x_{2}=A_{t} \sin \left(\omega_{d r} t+\varphi_{2}\right)$

$e x_{3}=A_{t} \sin \left(\omega_{d r} t+\varphi_{3}\right)$

$e x_{4}=A_{t} \sin \left(\omega_{d r} t+\varphi_{4}\right)$

$e x_{5}=A_{t} \sin \left(\omega_{d r} t+\varphi_{5}\right)$

$e x_{6}=A_{t} \sin \left(\omega_{d r} t+\varphi_{6}\right)$

Where,

At- Track roughness magnitude, $m$

$\mathrm{V}$ - Train forward speed, $\mathrm{m} / \mathrm{s}$

$\varphi_{n}$ - The phase angle of the nth wheel, rad.

$\omega_{d r}$ - Drive frequency, $\mathrm{rad} / \mathrm{s} ; \omega_{d r}=(2 \Pi \mathrm{V}) / L$

L- Track surface wavelength, $\mathrm{m}$

Track profile adopted in the formulation process has a continuous sinusoidal variation as depicted in Figure3.

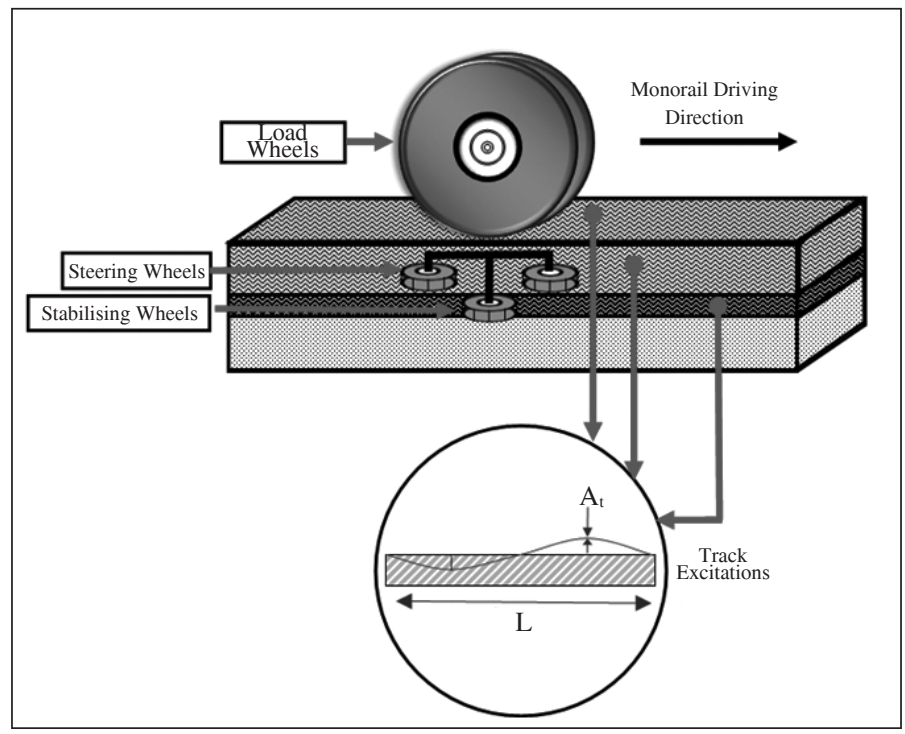

Figure 3: Track Profile configuration

Since EOM is defined as:"

$M \ddot{x}+C \dot{x}+K x=f(t)$

Where,

M- System mass matrix.

C-System damping matrix.

$\ddot{x}$ - Acceleration vector. $\dot{x}$-Velocity vector.

K-System stiffness matrix.

$\boldsymbol{x}$ - Displacement vector. $f(t)$ - Track excitation matrix is defined as follows:-

$$
f(t)=\left[\begin{array}{c}
e x_{1}(t) \\
e x_{2}(t) \\
e x_{3}(t) \\
e x_{4}(t) \\
e x_{5}(t) \\
e x_{6}(t) \\
0 \\
0 \\
0 \\
0 \\
0 \\
0 \\
0 \\
0 \\
0
\end{array}\right]=\left[\begin{array}{c}
A_{t} \sin \left(\omega_{d r} t+\varphi_{1}\right) \\
A_{t} \sin \left(\omega_{d r} t+\varphi_{2}\right) \\
A_{t} \sin \left(\omega_{d r} t+\varphi_{3}\right) \\
A_{t} \sin \left(\omega_{d r} t+\varphi_{4}\right) \\
A_{t} \sin \left(\omega_{d r} t+\varphi_{5}\right) \\
A_{t} \sin \left(\omega_{d r} t+\varphi_{6}\right) \\
0 \\
0 \\
0 \\
0 \\
0 \\
0 \\
0 \\
0 \\
0
\end{array}\right]
$$

The vector G (gravity) does not appear because the initial positions are chosen as the system equilibrium positions. The use of the Monorail suspension system matrices is mandatory to acquire a formal representation of the system's dynamic equations.

\subsection{Central Difference Method}

For system solutions and simulation processes [18], of the formulated model in this paper, the process of mathematical modeling and properties considerations, were achieved by using Guyan reduction to increase computational efficiency. Central Difference method can be used to solve differential equations of bogie suspension system. The time interval can be assumed with medium values to accelerate the computation process.

The central difference method is one of many numerical integration algorithms that can be used in numerical analysis to solve numerical differential equations. Furthermore, it can be utilised to conduct a dynamic simulation of the monorail model [18]. The central difference method is a numerical method which has the form of [13] [16]"

$$
\dot{X} \approx \frac{x_{t+\Delta t-x_{t-\Delta t}}}{2 \Delta t}
$$

$$
\ddot{X} \approx \frac{x_{t+\Delta t}-2 x_{t}+x_{t-\Delta t}}{(\Delta t)^{2}}
$$

Where $\Delta \mathrm{t}$ is the sampling time which must comply with:

$$
\Delta \leq \frac{1}{10} T_{\min }
$$

Tmin is the minimal period possessed in all modes. The sampling Time $\Delta \mathrm{t}$ can be set to 0.005 seconds, which is sufficiently less than 0.1 Tmin. The value of $\Delta \mathrm{t}$ is chosen as 0.005 to obtain stable and accurate solutions while satisfying the condition in Equation (18) [20]. 


\subsection{SIMULATION STRATEGY}

For consistency, physical properties were adopted based on a model from [7]. After that three cases were chosen to simulate the formulated model, where the Monorail Suspension system displacements were investigated under different loads, speeds and track sinusoidal excitations. load values were selected based on the adopted model that was designed to test the impact of loading on monorail bridge displacements, however, the focus here is on the Monorail suspension system displacements. These simulation scenarios are tabulated in Table1.

Table1: Monorail simulation scenarios

\begin{tabular}{|c|l|c|c|c|c|c|c|c|c|c|}
\hline No. & Properties & \multicolumn{3}{|c|}{ CASE 1 } & \multicolumn{3}{|c|}{ CASE 2 } & \multicolumn{3}{|c|}{ CASE 3 } \\
\hline 1. & Speed $(\mathrm{km} / \mathrm{h})$ & 36 & 54 & 72 & 36 & 54 & 72 & 36 & 54 & 72 \\
\hline 2. & Speed $(\mathrm{m} / \mathrm{s})$ & 10 & 15 & 20 & 10 & 15 & 20 & 10 & 15 & 20 \\
\hline 3. & Load Case & $\begin{array}{c}\text { No } \\
\text { passengers }\end{array}$ & $\begin{array}{c}\text { Normal Load } \\
129 \\
\text { passengers }\end{array}$ & $\begin{array}{c}\text { Fully } \\
\text { loaded } \\
270 \\
\text { passengers }\end{array}$ \\
\hline 4. & $\begin{array}{l}\text { Load Value } \\
\text { KN) }\end{array}$ & $262.4 \mathrm{KN}$ & $338.3 \mathrm{KN}$ & \multicolumn{2}{|c|}{$420.7 \mathrm{KN}$} \\
\hline
\end{tabular}

There are mainly 6 excitations that are in sinusoidal nature. The reason why they are 6 track excitations against 15 degrees of freedom Suspension system, is due to need to affect the points, where the monorail tiers interact with the track only, where their interaction is bounded by the Monorail body bounce, front bogie bounce, rear bogie bounce, monorail body lateral translation, Front bogie lateral displacement, and rear bogie lateral displacement only. In addition, the magnitude of induced displacement on the Monorail suspension system is chosen to be $0.05 \mathrm{~m}$ to simulate a rough track surface on the monorail suspension system as seen in Figure 4.

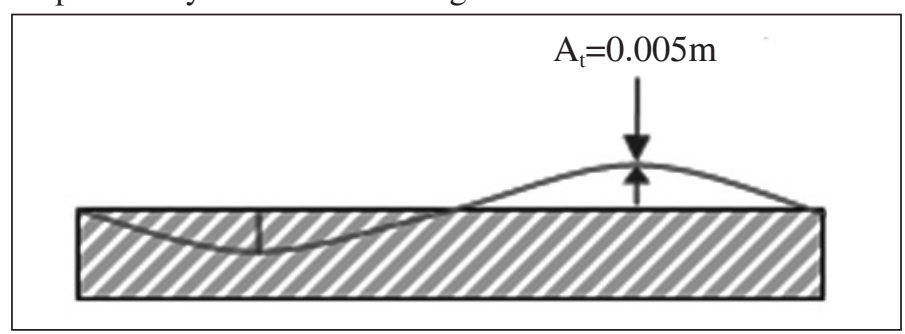

Figure 4: Track surface excitations

Track induced excitations signals are generated using Equation (1) for driving speeds $36 \mathrm{~km} / \mathrm{h}(10 \mathrm{~m} / \mathrm{s}), 54 \mathrm{~km} / \mathrm{h}(15 \mathrm{~m} / \mathrm{s})$ and $72 \mathrm{~km} / \mathrm{h}(20 \mathrm{~m} / \mathrm{s})$ respectively. It should be noted that the drive frequency can be interpreted in two ways. For a particular track with constant wavelength $\mathrm{L}$, the higher drive frequency means the train is running at higher speed, while the lower drive frequency, on the contrary, means the Monorail is running at lower speed. Alternatively, if the train speed is constant, the higher drive frequency means the track surface possesses short wavelength characteristics, while the lower drive frequency means the track surface possesses long wavelength characteristics. Therefore, the interpretation of the simulation results is strongly related to the simulated conditions and assumptions. In this thesis, the track wavelength is fixed at $42.8 \mathrm{~m}$.
After simulation execution, results are collected in the form of dynamic responses with respect to time, Fast Fourier Transform (FFT) is then performed to distinguish the frequency range, that the Monorail Suspension system is vibrating on.In addition the magnitude of displacement as acceleration. After that, results are compared with each case to form conclusions and understand the dynamic behavior of the suspension system under different cases.

\subsection{RESULTS AND ANALYSIS}

Dynamic responses are summarized in this section below based on simulation results, where Case (1) example is provided in A.3 for illustration.

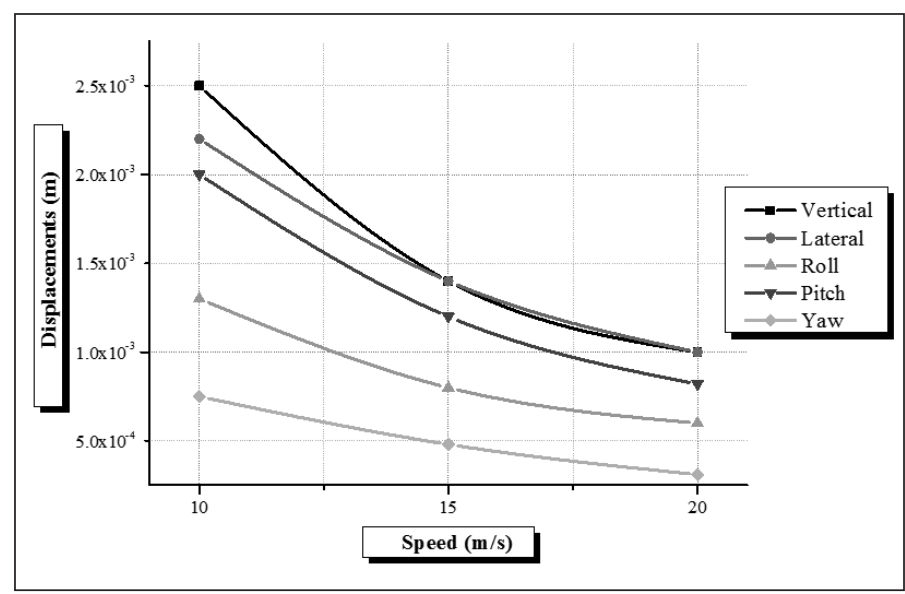

Figure 5: Monorail Body Displacements (m) verses Speed (m/s) (No passengers)

\subsection{Case (1) (No passengers) Results}

\subsubsection{Monorail Body Dynamic Response}

Figure 5 illustrates monorail body displacements from their dynamic responses amplitudes and display their changes under different deriving speeds below and under no passenger's condition. Based on Figure 5, it can be seen that the Monorail body displacements tend to drop with the increase of speed creating an inversely proportional relationship with speed. In addition, it can be seen that displacements are within the range of $0.31 \mathrm{~mm}$ to $2.5 \mathrm{~mm}$. It should be noted that these displacements are not static, but rather dynamic where they fluctuate around the mentioned range.

Furthermore, vertical and lateral displacements hold the highest value of displacement in comparison with roll, pitch, and yaw. The reason why Monorail body lateral displacements are high on low speeds is due to the special configuration of the monorail bogie, where it is U-shaped and its clamping mechanism is more effective on higher speeds. Under low driving speed of 10 $(\mathrm{m} / \mathrm{s})$, vertical, lateral and pitch displacements are dominant with a range of $2 \mathrm{~mm}$ to $2.5 \mathrm{~mm}$, where roll and yaw displacements are low with a mere range of $0.75 \mathrm{~mm}$ to $1.3 \mathrm{~mm}$. On the other hand, under medium and high driving speeds of 15 and $20(\mathrm{~m} / \mathrm{s})$ lateral and vertical displacements are almost equal with $0.1 \mathrm{~mm}$ difference, while roll, pitch, and yaw descend from $1.3 \mathrm{~mm}, 2 \mathrm{~mm}$ and $0.75 \mathrm{~mm}$ to $0.6 \mathrm{~mm}, 0.82 \mathrm{~mm}$ and $0.31 \mathrm{~mm}$ respectively. 


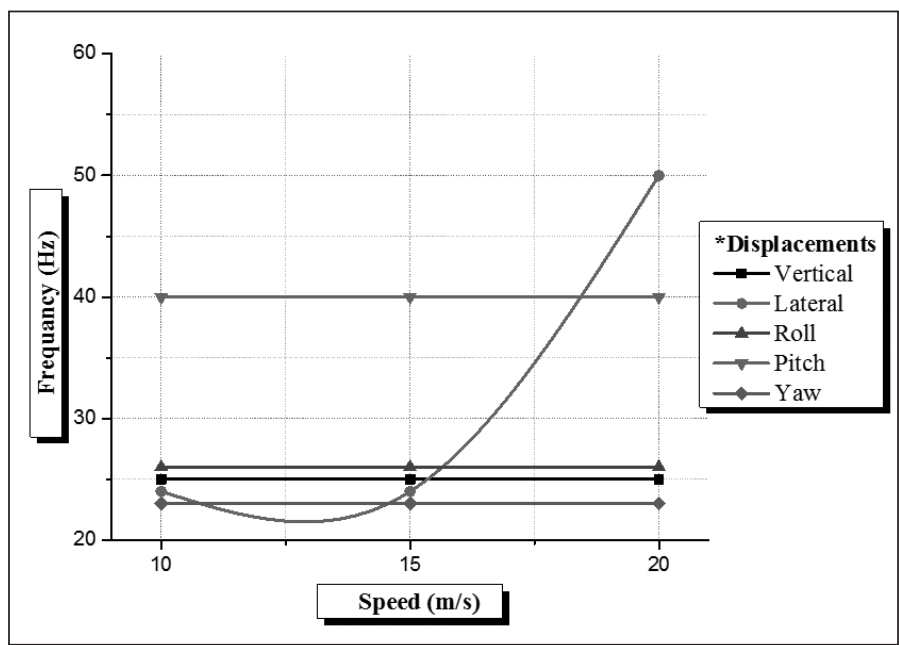

Figure 6: Monorail Body Displacements Frequency $(\mathrm{Hz})$ versus Speed $(\mathrm{m} / \mathrm{s})$ (no passengers)

Figure 6 depicts monorail body frequency ranges from their FFT (SeeA.3) graphs in comparison with driving speeds under no passenger's condition. It illustrates the frequency range of the monorail displacements (or vibrations) through different driving speeds. It can be seen that vertical, roll, pitch and yaw vibrations are in a static range of $25 \mathrm{~Hz}$ to $40 \mathrm{~Hz}$ and they remain within that range under all driving speeds. This behavior is expected from monorail body, because it does not come in contact with the imposed track excitations directly, but its displacement is based on the displacements of the front and rear bogies, where it's based is linked to them.

\subsubsection{Front Bogie Dynamic Response}

Monorail front bogie suspension system is the first part of the Monorail suspension system that comes in contact with the track surface excitations, thus it is expected to have more displacements than the monorail body as seen in Figure 7. In addition, it has a different response in comparison with monorail body displacements, where they had the same relation with speed as seen before in Figure 5. Furthermore, the range of displacements is wider, where its starts from $0.02 \mathrm{~mm}$ up to 8 $\mathrm{mm}$. Vertical, lateral and pitch displacements are the highest among other displacements, where they represent the load wheels and guide wheels respectively. Roll increases in $15(\mathrm{~m} / \mathrm{s})$ speed with $4.8 \mathrm{~mm}$, but drops to $2.9 \mathrm{~mm}$ in $20(\mathrm{~m} / \mathrm{s})$ from its

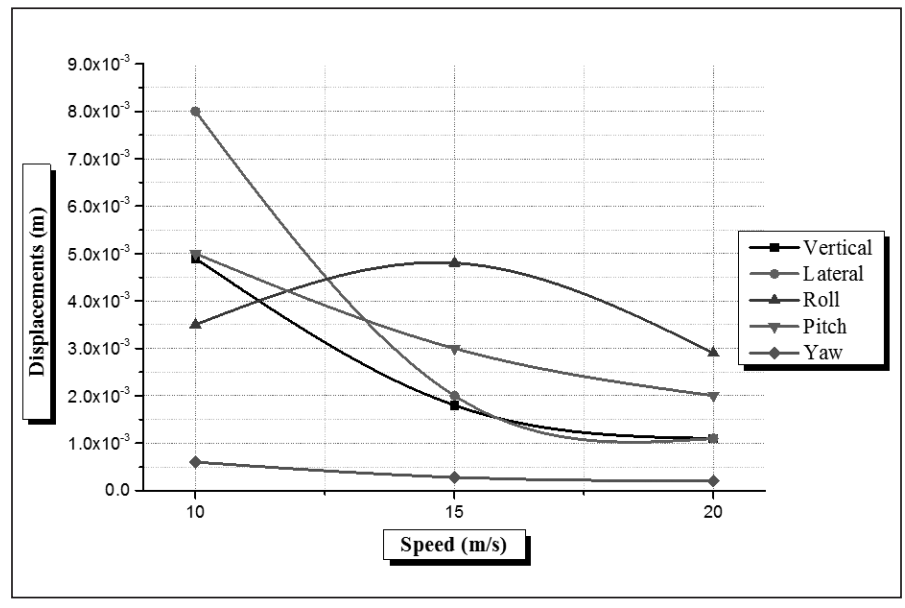

Figure 7: Front Bogie Displacements (m) versus Speed $(\mathrm{m} / \mathrm{s})$ (No passengers)

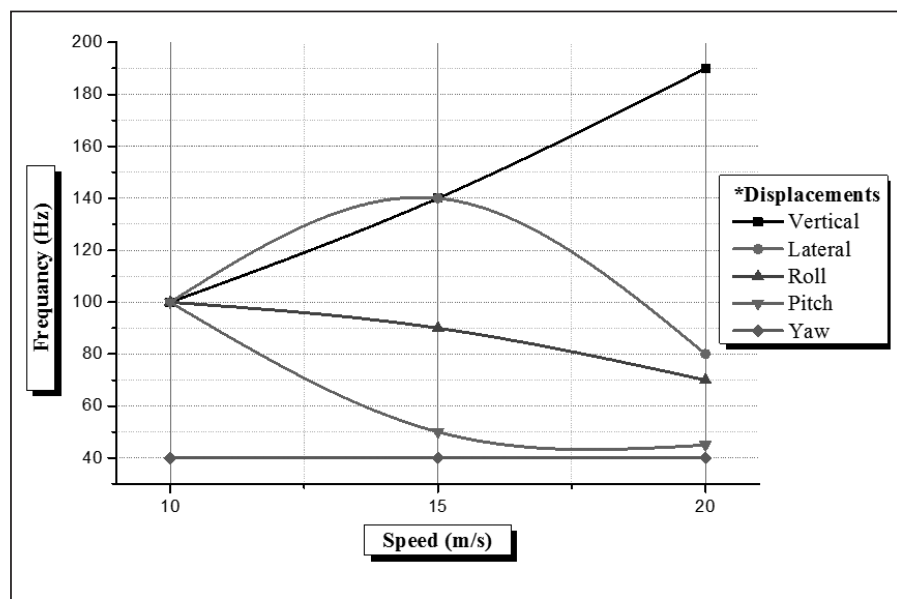

Figure 8: Front Bogie Displacements Frequency $(\mathrm{Hz})$ versus Speed ( $\mathrm{m} / \mathrm{s})$ (no passengers)

initial displacement with $3.5 \mathrm{~mm}$ in $10(\mathrm{~m} / \mathrm{s})$. Yaw is the lowest displacement in this case with a mere $0.6 \mathrm{~mm}$ to $0.02 \mathrm{~mm}$, which is negligible.

Based on Figure 8, it can be seen that driving speed is directly proportional with vertical displacements, where the bogie vibrates in the range of $100 \mathrm{~Hz}$ up to $190 \mathrm{~Hz}$ form speeds $10(\mathrm{~m} / \mathrm{s})$ to $20(\mathrm{~m} / \mathrm{s})$ in the form of bouncing. However, lateral displacement increases from $10(\mathrm{~m} / \mathrm{s})$ to $(15 \mathrm{~m} / \mathrm{s})$ then decreases in high speeds within the range of $100 \mathrm{~Hz}$ to $80 \mathrm{~Hz}$, this is due to the tendency of the bogie guide and stabilising wheels to sway in a lateral direction before they stabilise. In addition, the guide and stabilizing wheels clamp-on track more effectively on high speeds, thus lower lateral vibration frequency in high speeds. Roll and pitch frequencies decrease with the increase of speed. On the other hand, yaw displacements vibrate are static with $40 \mathrm{~Hz}$.

\subsubsection{Rear Bogie Dynamic Response}

Figure 9 illustrates the results from the dynamic responses of the Monorail's Rear bogie in terms of lateral, vertical, roll, pitch and yaw displacements. Displacements of rear bogie are distributed between minor and major vibrations. Major displacements in lateral and vertical degrees within the range of $1 \mathrm{~mm}$ to $4.5 \mathrm{~mm}$, where vertical displacements drop linearly with increase of speed, however, lateral displacements gradually drop in $15(\mathrm{~m} / \mathrm{s})$, then slightly increase in $20(\mathrm{~m} / \mathrm{s})$. On the other hand, minor displacements are minimal with values below $1 \mathrm{~mm}$. Rear bogie

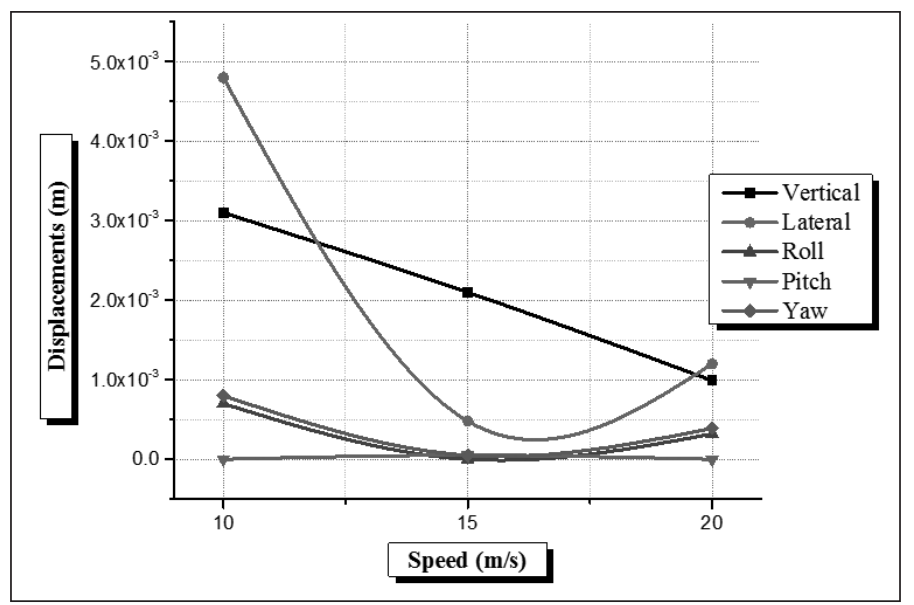

Figure 9: Front Bogie Displacements (m) versus Speed $(\mathrm{m} / \mathrm{s})$ (No passengers) 


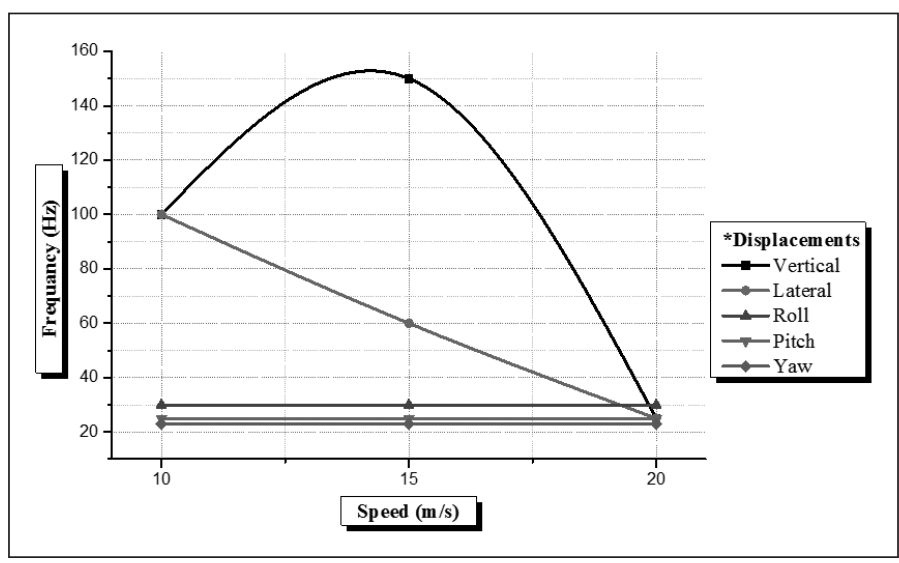

Figure 10: Rear Bogie Displacements Frequency (m) versus Speed $(\mathrm{m} / \mathrm{s})$ (No passengers)

is the second part of the monorail system that comes in contact with the track surface, but due to the balanced weight distribution of the monorail body, its vertical and lateral displacements are similar to the front bogie, except for roll and pitch values, where they are less. This is caused by, the absorption of displacements in the front bogie and monorail body.

Figure 10 illustrates the frequency ranges of rear bogie displacements. Vertical and lateral displacements vibrate within the range of $100 \mathrm{~Hz}$ to $20 \mathrm{~Hz}$, where lateral displacements gradually drop with the increase of speed, however, vertical displacements slightly increase from $10(\mathrm{~m} / \mathrm{s})$ to $15(\mathrm{~m} / \mathrm{s})$ then drops back to $20 \mathrm{~Hz}$ in $20(\mathrm{~m} / \mathrm{s})$. That means more bounce oscillations are expected in $15(\mathrm{~m} / \mathrm{s})$ driving speed than other speeds, but less lateral sway with an increase of speed. In addition, pitch, roll, and yaw vibrate frequency remains stable with the increase of speed within the range of $23 \mathrm{~Hz}$ to $25 \mathrm{~Hz}$.

\subsection{Case (2) (129 passengers) Results}

In this case, the monorail is investigated with (129 passenger's) load, which is the normal load under low mid and high driving speed scenarios. The dynamic analysis describes the model's dynamic response versus time in comparison with speeds. Besides that Fast Fourier Transform is applied to acquire dynamic response frequencies, which the system displacements vibrate on in comparison to speeds with the acceleration magnitude of the displacements in $\left(\mathrm{cm} / \mathrm{s}^{2}\right)$.

\subsubsection{Monorail Body Dynamic Response}

Figure 11 describes Monorail body displacements. Dynamic responses of the monorail body are similar to an empty train in case (1) in terms of their relationship with speed, where they are inversely proportional with speed. However, the magnitudes of displacements are larger, due to the compensation of the suspension system stiffness and damping levels with respect to the imposed passengers load. In $10(\mathrm{~m} / \mathrm{s})$ speed displacements occur within the range of $0.9 \mathrm{~mm}$ to $3.1 \mathrm{~mm}$ and they gradually drop with the increase of speed down to a range of $0.22 \mathrm{~mm}$ to $1.3 \mathrm{~mm}$.

By comparison, (Figure 12) and (Figure 6) of normal operation and empty train conditions share some similarities in terms of stable ranges for all displacements, except for lateral displacements, where they are more stable in normal operation load than an empty train. This is due to the suspension system stiffness compensation against passenger's load. Besides that, displacements vibrate within a range of $15 \mathrm{~Hz}$ to $25 \mathrm{~Hz}$.

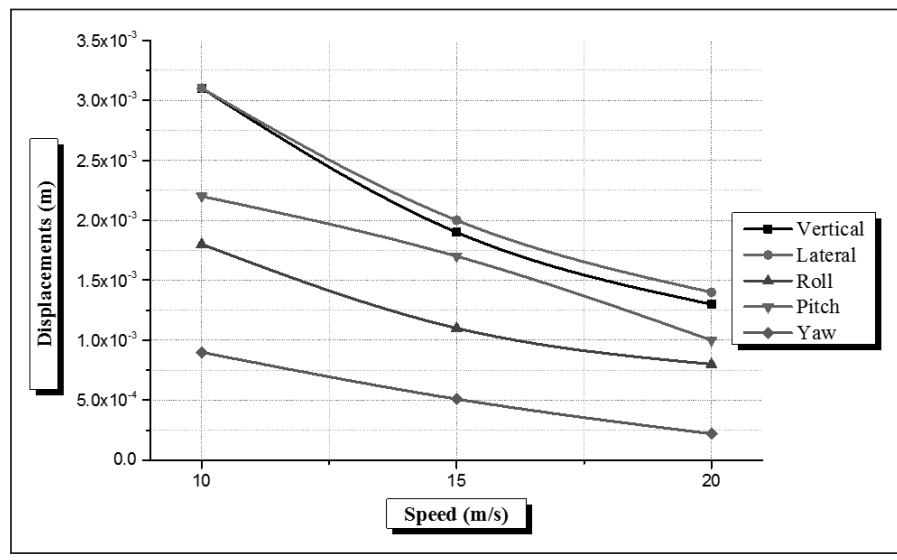

Figure 11: Monorail Body Displacements (m) versus Speed $(\mathrm{m} / \mathrm{s})$ (129 passengers)

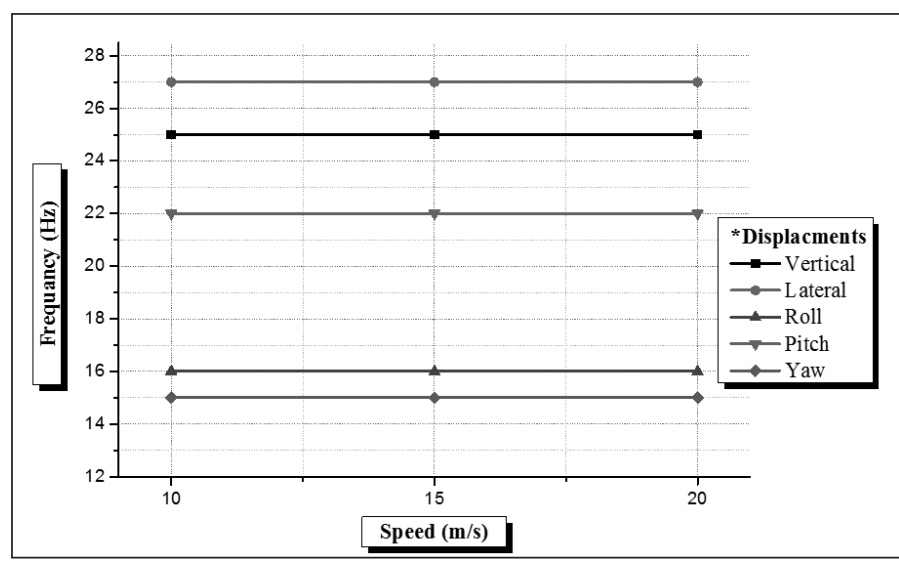

Figure 12: Monorail Body Displacements Frequency $(\mathrm{Hz})$ versus Speed $(\mathrm{m} / \mathrm{s})$ (129 passengers)

\subsubsection{Front Bogie Dynamic Response}

By comparing, Figure 13 with empty train case (1) in Figure 7 It can be seen that lateral displacements magnitude has dropped from $8 \mathrm{~mm}$ to $1 \mathrm{~mm}$ in $10(\mathrm{~m} / \mathrm{s})$, due to an imposed load of passengers. However, it is directly proportional to driving speed where it increases to $1.6 \mathrm{~mm}$ again in $20(\mathrm{~m} / \mathrm{s})$. Other displacements tend to react inversely with speed. Besides that, roll motion slightly increases in $20(\mathrm{~m} / \mathrm{s})$. In addition, vertical, roll, pitch and yaw displacements magnitudes are higher than their empty train magnitudes, where their values are in the range of $7 \mathrm{~mm}$ to $0.5 \mathrm{~mm}$. Front bogie tends to bounce, pitch and roll more under normal operation.

The front bogie displacements frequency range in normal operation load is slightly higher than an empty train based on

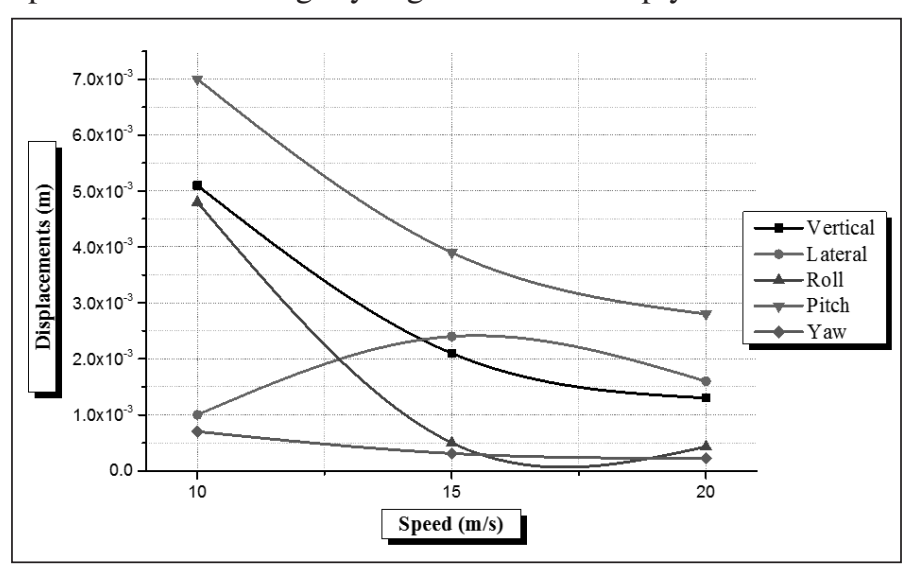

Figure 13: Front Bogie Displacements (m) versus Speed $(\mathrm{m} / \mathrm{s})(129$ passengers) 


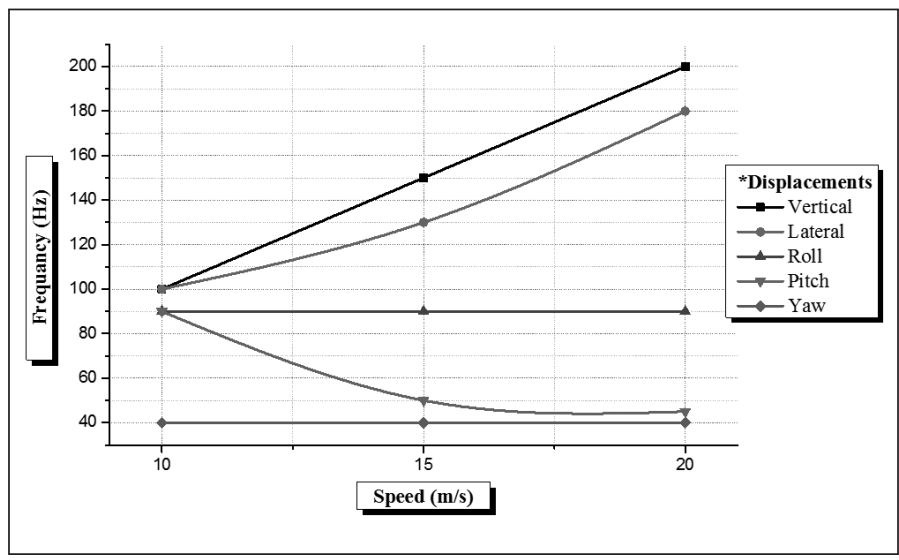

Figure 14: Front Bogie Displacements Frequency $(\mathrm{Hz})$ versus Speed $(\mathrm{m} / \mathrm{s})$ (129 passengers)

Figure 14, Vertical and lateral displacements increase with driving speed within the range of $100 \mathrm{~Hz}$ to $200 \mathrm{~Hz}$ and their differences are minimal in terms of frequency values. However, there are small low frequencies that are negligible. Besides that, pitch frequency of the front bogie reduces from $90 \mathrm{~Hz}$ to $45 \mathrm{~Hz}$ with the increase of driving speed. On the other hand, roll and yaw displacements remain stable with values of $90 \mathrm{~Hz}$ and $40 \mathrm{~Hz}$ respectively. In other words, the front bogie suspension system displacements increase in terms of bouncing and swaying but slight changes in terms of rotational responses.

\subsection{Rear Bogie Dynamic Response}

Rear bogie dynamic responses are illustrated in Figure15 Displacements are inversely proportional with speed. Dominant displacements are vertical and lateral within the range of $6 \mathrm{~mm}$ to $1.4 \mathrm{~mm}$. Minor displacements are roll, pitch, and yaw, which drop slightly from $1 \mathrm{~mm}$ to $0.05 \mathrm{~mm}$.

It can be seen that in Figure 16 vertical and lateral displacements are dominant and they vibrate in the range of $60 \mathrm{~Hz}$ to $180 \mathrm{~Hz}$. Vertical displacements increase linearly with speed, but lateral displacements drop inversely from $10(\mathrm{~m} / \mathrm{s})$ to $15(\mathrm{~m} / \mathrm{s})$, then remains stable around $60 \mathrm{~Hz}$ in $20(\mathrm{~m} / \mathrm{s})$, which is higher than empty train case (1) rear bogie value in Figure10. This is due to the imposed load of 129 passengers. In addition, pitch, roll and yaw are relatively stable between $23 \mathrm{~Hz}$ to $35 \mathrm{~Hz}$, which is correlated with their minimal values in Figure 15.

\subsection{Case (3) (270 passangers) Results}

In this case, the monorail is investigated with 270 passenger's

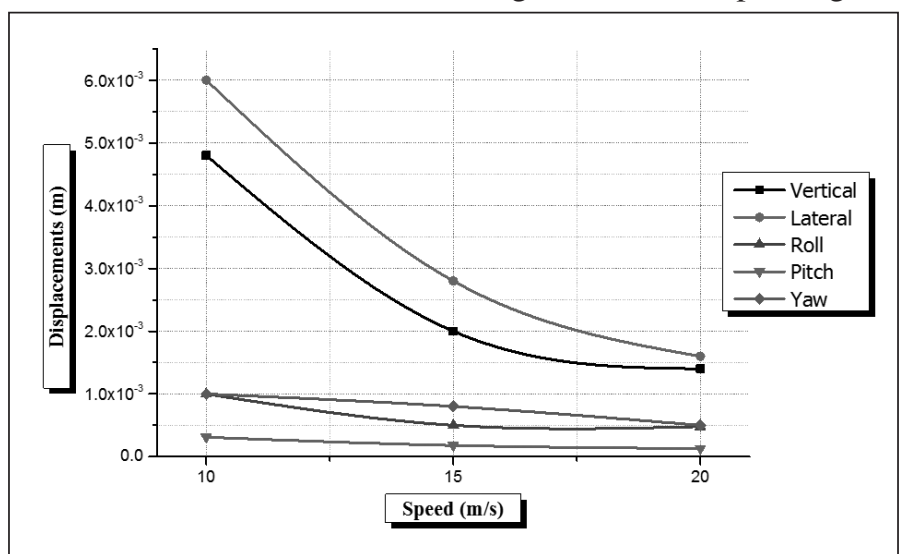

Figure 15: Rear Bogie Displacements (m) versus Speed $(\mathrm{m} / \mathrm{s})(129$ passengers)

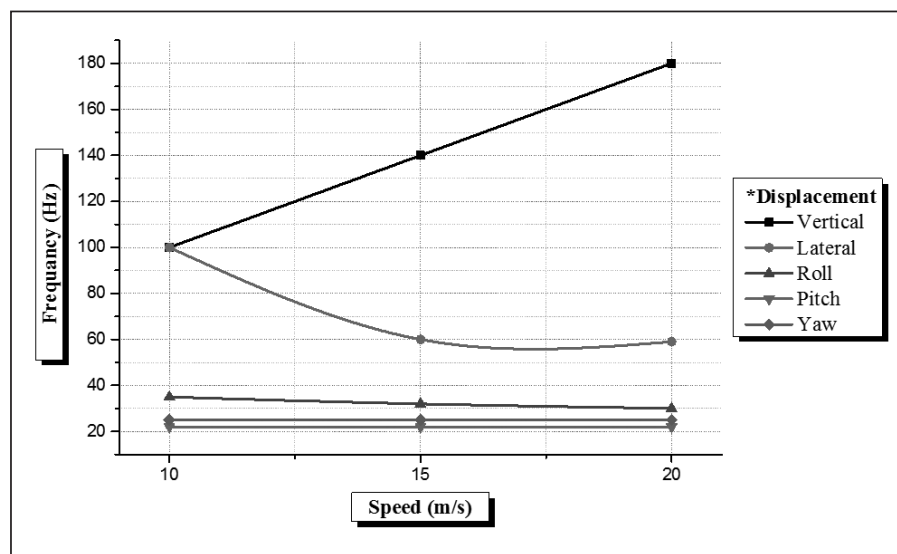

Figure 16: Rear Bogie Displacements Frequency $(\mathrm{Hz})$ versus Speed $(\mathrm{m} / \mathrm{s})(129$ passengers $)$

load, which an abnormal load under low mid and high is driving speed scenarios. The dynamic analysis describes the model's dynamic response versus time in comparison with speeds. On the other hand, fast Fourier transform is applied to acquire dynamic response frequencies, which the system displacements vibrate on in comparison to speeds.

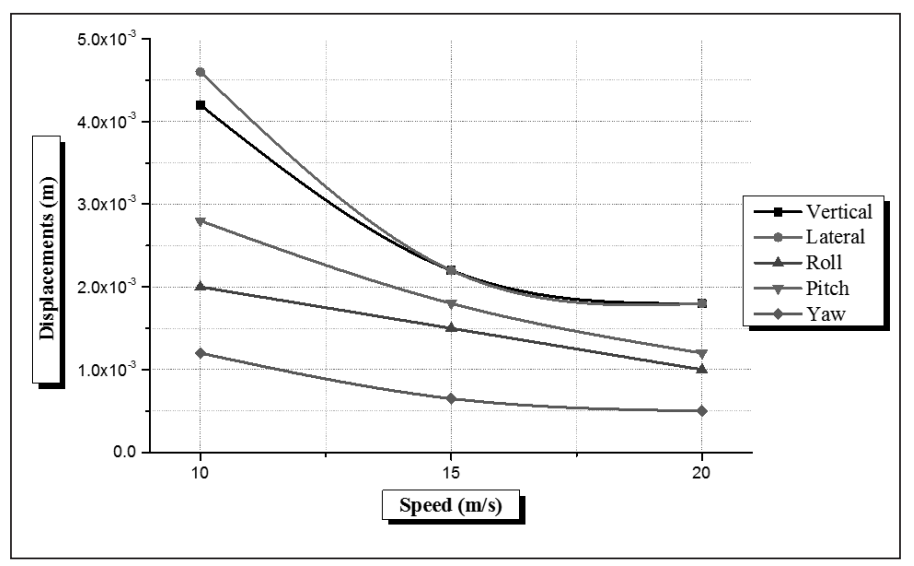

Figure 17: Monorail Body Displacements (m) versus Speed $(\mathrm{m} / \mathrm{s})$ (270 passengers)

\subsubsection{Monorail Body Dynamic Response}

By comparing Figures 5 and Figure 11, for monorail body displacements from no passengers case and normal load case to Figure17. Relationships of displacements to speed are similar in terms of proportions against speed. However, they differ in terms of magnitudes and dominant displacements, where displacements magnitudes increase with the increase of load. In this case, the displacements range is between $0.5 \mathrm{~mm}$ to $4.8 \mathrm{~mm}$. This is a result of overloading the suspension system, which reduces its efficiency in isolating bogies displacements. In addition, vertical and Lateral displacements values match in driving speeds of $15(\mathrm{~m} / \mathrm{s})$ and $20(\mathrm{~m} / \mathrm{s})$ respectively.

Figure 18 describes the frequency range of front bogie responses. By comparing it with Figures 6 and Figure 12, from empty train and normal load cases respectively. It can be seen in Figure 12 that in normal load all displacements had stable frequencies through different speeds. However, in Figure 6 only lateral displacements frequencies increased with speed and the rest remained stable. In this case, vertical yaw and roll displacements frequency remained stable with the change of speed within a range of $8 \mathrm{~Hz}$ to $25 \mathrm{~Hz}$. However, pitch displacements frequency 


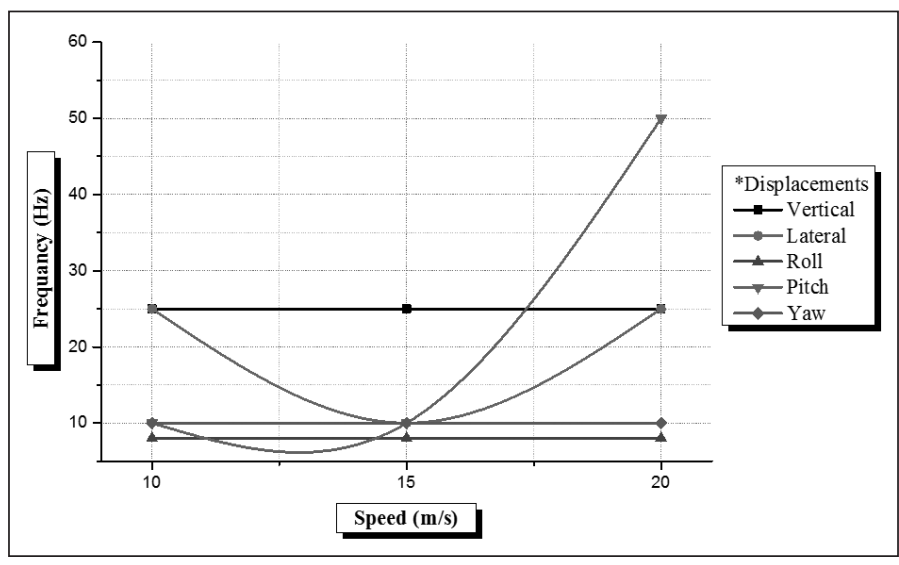

Figure 18: Monorail Body Displacements Frequency $(\mathrm{Hz})$ versus Speed ( $\mathrm{m} / \mathrm{s})(270$ passengers $)$

increased with driving speeds up to $50 \mathrm{~Hz}$ in $20(\mathrm{~m} / \mathrm{s})$. In addition, lateral displacement frequency decreases to $10 \mathrm{~Hz}$ in $15(\mathrm{~m} / \mathrm{s})$ but remains at $25 \mathrm{~Hz}$ in $10(\mathrm{~m} / \mathrm{s})$ and $20(\mathrm{~m} / \mathrm{s})$ driving speeds.

\subsubsection{Front Bogie Dynamic Response}

By comparing Figure 19 with Figure 7 and Figure 1, it can be seen that Front bogie displacements possess higher displacements range that is between $1 \mathrm{~mm}$ to $14 \mathrm{~mm}$. That's is due to the overload of passengers, which reduces the suspension system impact absorption.

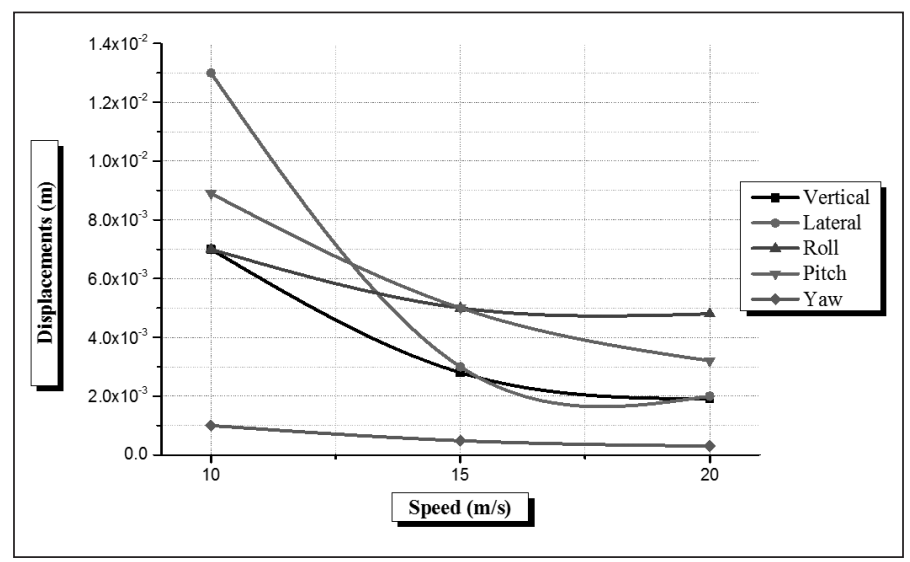

Figure 19: Front Bogie Displacements (m) versus Speed $(\mathrm{m} / \mathrm{s})(270$ passengers)

Figure 20 illustrates the frequency ranges of front bogie displacements and they are within the range of $40 \mathrm{~Hz}$ to $200 \mathrm{~Hz}$ with similar characteristics of Figure 14 except for roll displacements frequency, where they drop with the increase of speed.

\subsubsection{Rear Bogie Dynamic Response}

Figure 21 illustrates Rear bogie displacements, based on their dynamic responses. In this case, rear bogie displacements are slightly higher than Figure 15 case with $1 \mathrm{~mm}$ difference.

Figure 22 displays rear bogie displacements frequencies. By comparison with Figure 9. It can be seen that displacements frequencies possess similar characteristics in terms of their relationship with speeds also their frequencies range, where they vibrate in the range of $19 \mathrm{~Hz}$ up to $140 \mathrm{~Hz}$.

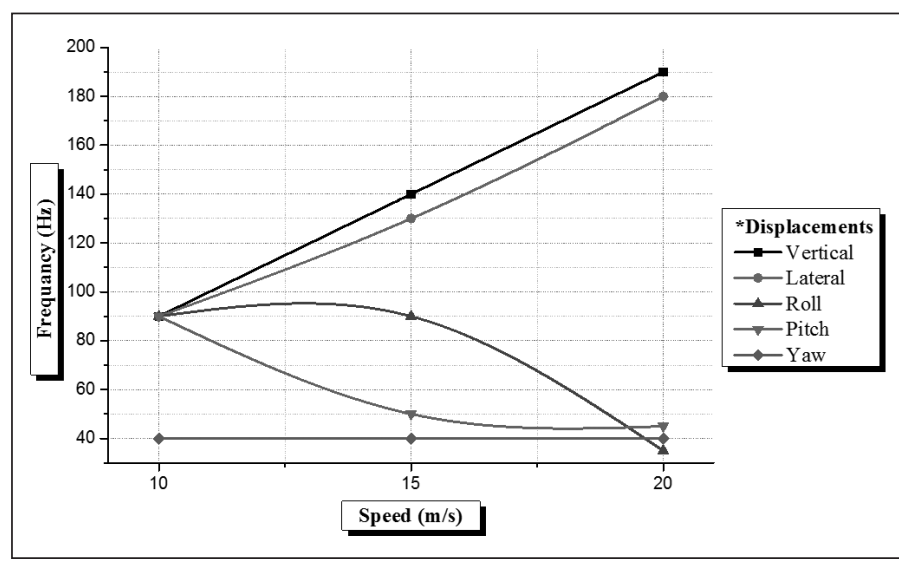

Figure 20: Front Bogie Displacements Frequency $(\mathrm{Hz})$ versus Speed $(\mathrm{m} / \mathrm{s})(270$ passengers $)$

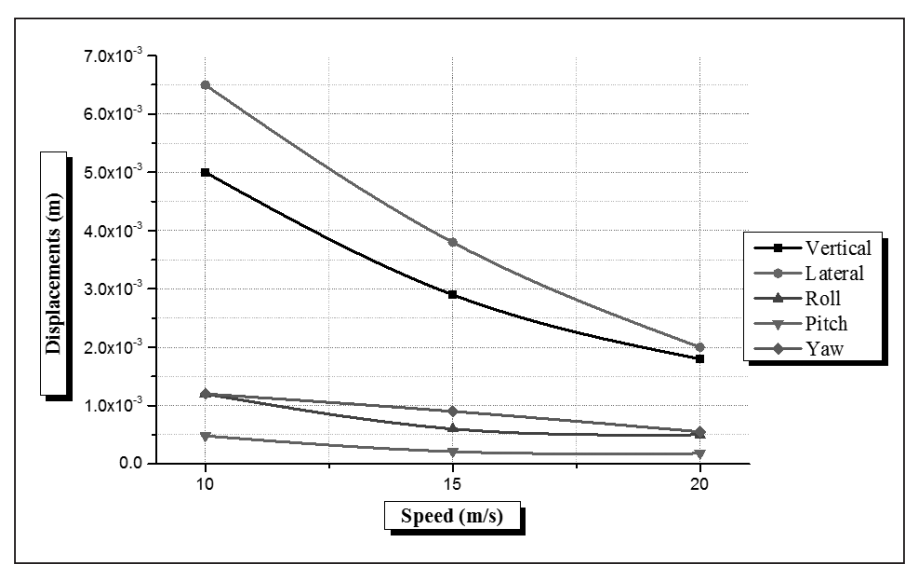

Figure 21: Rear Bogie Displacements (m) verses Speed $(\mathrm{m} / \mathrm{s})(270$ passengers)

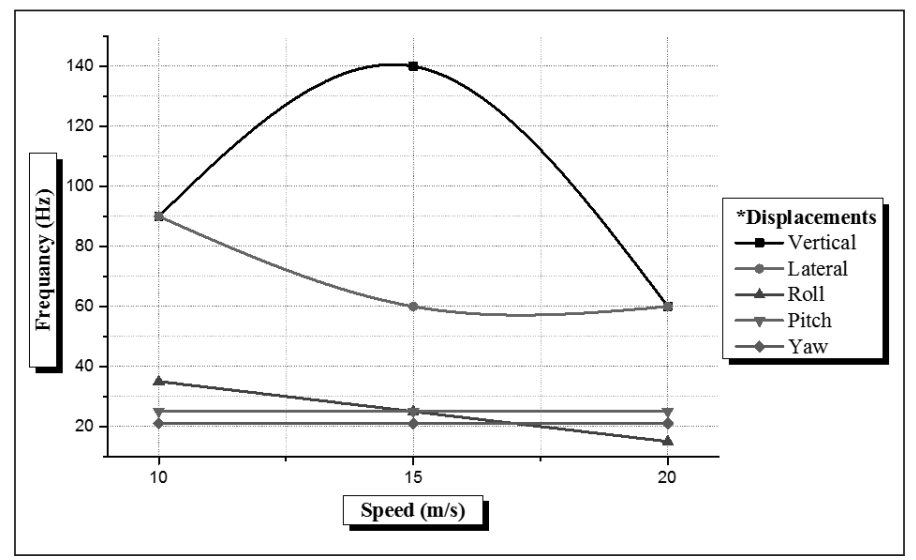

Figure 22: Rear Bogie Displacements Frequency $(\mathrm{Hz})$ versus Speed $(\mathrm{m} / \mathrm{s})(270$ passengers $)$

\subsection{Effects of Passengers Loading on Monorail Train}

Based on the previous cases, where the dynamic responses were simulated under passengers loading of 129, 270 and no passengers with respect to speeds $36 \mathrm{~km} / \mathrm{h}(10 \mathrm{~m} / \mathrm{s}), 54 \mathrm{~km} / \mathrm{h}$ $(15 \mathrm{~m} / \mathrm{s})$ and $72 \mathrm{~km} / \mathrm{h}(20 \mathrm{~m} / \mathrm{s})$ respectively shows that the amplitude of dynamic lateral displacements apparently decreases due to passenger's loading. Moreover, the inertia of the Monorail tends to have more effect on the rear bogie in exceptional loading cases. Nevertheless, no other clear changes are observed for dynamic response in the vertical direction. 


\section{SIMULATION OF MATHEMATICAL MODEL FOR MONORAIL SUSPENSION SYSTEM UNDER DIFFERENT TRACK CONDITIONS}

\subsection{EFFECTS OF SPEED ON MONORAIL TRAIN}

Based on simulation cases 1,2 and 3 , for speeds $36 \mathrm{~km} / \mathrm{h}(10 \mathrm{~m} / \mathrm{s})$, $54 \mathrm{~km} / \mathrm{h}(15 \mathrm{~m} / \mathrm{s})$ and $72 \mathrm{~km} / \mathrm{h}(20 \mathrm{~m} / \mathrm{s})$, helped to establish an inversely proportional relationship between displacement magnitude and train speeds for all cases. Additionally, the increase in speed produced profiles of high-frequency vibrations, where the vibrations possessed low frequencies for low speeds.

\subsection{CONCLUSION}

In conclusion, the performance of the Monorail suspension system model under different track conditions was carried out, by simulation of $15 \mathrm{DOF}$ Monorail suspension system model [22]. This was done to achieve a better understanding of how the monorail suspension system dynamic response reacts to different loads and driving speeds under track excitations. Also, to provide a tool that helps to solve issues in Monorail suspension design optimisation process.

It is found that the occurrence of resonance in vertical and lateral directions is very low between the monorail train body and its bogies. Besides that, rear bogie was found to be affected by exceptional loads tremendously, where this problem affects the Monorail body and front bogie stability. Furthermore, the ability of impacts absorption of front bogie suspension system reflects on the stability of the Monorail body. Another finding is that an empty Monorail car possesses unstable displacements similarly, in overloaded train instability and inefficient suspension dynamic responses in terms of loss of track disturbances isolation ability. Thus, more fluctuations appear in the model dynamic responses frequencies. However, these fluctuations can be used as indications of issues of Monorail suspension systems. Limitations of the model narrow the spectrum of Monorail suspension system characteristics but it can be further optimised in future research works.

\subsection{REFERENCES}

[1] Gilchrist AO, Hobbs AE, King BL, Washby V. Paper 2: The Riding of Two Particular Designs of Four-Wheeled Railway Vehicle. In Proceedings of the Institution of Mechanical Engineers, Conference Proceedings 1965 Jun (Vol. 180, No. 6, pp. 99-113). Sage UK: London, England: SAGE Publications.

[2] Jenkins, H. H., Stephenson, J.E, Clayton, G. A., Moreland, G. W., and Lyon, D., "The effect of truck and vehicle parameters on wheel/rail vertical dynamic forces", Railway Eng. J, 2-16, 1974, January.

[3] Simon Iwnicki, "Handbook of Railway vehicle Dynamics", CRC Press, 25-39,(23 May 2006.

[4] Rao, S. S., "Vibration Control" mechanical vibrations, 5th ed, p.772, 2010.
[5] H. Claus and W. Schiehlen, "Modeling and Simulation of Railway bogie Structural Vibrations," vehicle system dynamics, vol. 29, no. Sup1. Pp. 538-552, 1998.

[6] M. Naeimi, M. Tatari, a. Esmaeilzadeh, and M. Mehrauli, "Dynamic interaction of the monorail-bridge system using a combined finite element multi-body-based model," Proc. Inst. Mech. Eng. Part K J. Multi-body Dyn., vol. 229, no. 2, pp. 132$151,2015$.

[7] C. H. Lee, C. W. Kim, M. Kawatani, N. Nishimura, and T. Kamizono, "Dynamic response analysis of monorail bridges under moving trains and riding comfort of trains," Eng. Struct., vol. 27, no. 14, pp. 1999-2013, 2005.

[8] C. W. Kim, M. Kawatani, "Effect of train dynamics on seismic response of steel monorail bridges under moderate ground motion," Earthquake Engineering \& Structural Dynamics, 35(10):1225-1245.2006-08.

[9] C. H. Lee, C. W. Kim, M. Kawatani, N. Nishimura, and T. Kamizono, "Dynamic response analysis of monorail bridges under moving trains and riding comfort of trains," Eng. Struct., vol. 27 , no. 14 , pp. 1999-2013, 2005-12.

[10] C. W. Kim, M. Kawatani, "Dynamic Response of a monorail steel bridge under a moving train" Journal of Sound and Vibration 294(3):562-579,2006-06.

[11] W.C. Hurty, M.F. Rubinstein, Dynamics of structures. PrenticeHall, Englewood Cliffs, 1960, pp. 90-103.

[12] W.T. Thomson, Theory of Vibration with Applications. PrenticeHall, Englewood Cliffs, 1988, pp. 196-198.

[13] M. Kawatani, C.W. Kim, Computer simulation for dynamic wheel loads of heavy trains. Structural Engineering and Mechanics 12 (2001) 409-428.

[14] C.W. Kim, M. Kawatani, K.B. Kim, Three-dimensional dynamic analysis for bridge-vehicle interaction with roadway roughness. Computers\& Structures 83 (2005) 1627-1645.

[15] Guyan RJ. Reduction of stiffness and mass matrices. Aiaa journal 1965;3(2):380

[16] Newark NM. A Method of computation for structural dynamics. Asce J of Eng Mech Div 1970;96:593-620.

[17] Claus, H., \& Schiehlen, W. (1998). Modeling and simulation of railway bogie structural vibrations. Vehicle System Dynamics.

[18] Majka, M., \& Hartnett, M. (2008). Effects of speed, load and damping on the dynamic response of railway bridges and vehicles. Computers \& Structures, 86(6), 556-572. doi:10.1016/j. compstruc.2007.05.002

[19] Durali M, Bahabadi MM. Investigation of train dynamics in passing through curves using a full model. InASME/IEEE 2004 Joint Rail Conference 2004 Jan. 1 (pp. 83-88). American Society of Mechanical Engineers. 


\section{PROFILES}

WAFI A. MABROUK is a postgraduate student at Faculty of Electrical and Electronic Engineering, University Tun Hussien Onn Malaysia. His areas of research are railway engineering systems integration, optical wireless communication technologies and train communication systems.

PROF. DR MOHAMMAD FAIZ LIEW BIN ABDULLAH is a professor in Communication Engineering Department, Faculty of Electrical Engineering University Tun Hussien Onn Malaysia. His research area includes wireless Optical Communication, Solar Cell Design, and Railway Signaling and Communication Systems. 


\section{APPENDIX A.1}

\section{A1.Monorail Train Model Properties.}

\begin{tabular}{|c|c|c|c|c|c|}
\hline Body parameters & Value & $\begin{array}{c}\text { Bogie } \\
\text { Parameters }\end{array}$ & Value & $\begin{array}{l}\text { Geometry } \\
\text { Parameters }\end{array}$ & Value \\
\hline $\begin{array}{l}m_{v 1 l} \\
(\mathrm{~kg})\end{array}$ & $14.22 \times 10^{3}$ & ${ }^{m} v 21^{, m} v 22(\mathrm{~kg})$ & $6.20 \times 10^{3}$ & $\begin{array}{c}L v x 1, L v x 2 \\
\text { (m) }\end{array}$ & 4.800 \\
\hline$I_{v x l l}\left(\mathrm{~kg} \cdot \mathrm{m}^{2}\right)$ & $1.997 \times 10^{4}$ & $I v x 21, I v x 22 \quad\left(\mathrm{~kg} \cdot \mathrm{m}^{2}\right)$ & $2.461 \times 10^{3}$ & $L v x 3 \quad(\mathrm{~m})$ & 0.7500 \\
\hline$I_{v y I I}\left(\mathrm{~kg} \cdot \mathrm{m}^{2}\right)$ & $1.717 \times 10^{5}$ & I vy $21, I$ vy $22\left(\mathrm{~kg} \cdot \mathrm{m}^{2}\right)$ & $3.488 \times 10^{3}$ & $L v x 4 \quad$ (m) & 1.250 \\
\hline$I_{v y l l}\left(\mathrm{~kg} \cdot \mathrm{m}^{2}\right)$ & $1.717 \times 10^{5}$ & $I v z 21, I v z 22\left(\mathrm{~kg} \cdot \mathrm{m}^{2}\right)$ & $9.688 \times 10^{3}$ & L vyl (m) & 1.490 \\
\hline$K_{v z l l}\left(\mathrm{~kg} \cdot \mathrm{m}^{2}\right)$ & $9.0 \times 10^{5}$ & $K v z 21, K v z 22\left(\mathrm{~kg} \cdot \mathrm{m}^{2}\right)$ & $5.170 \times 10^{6}$ & $L v y 2 \quad(\mathrm{~m})$ & 1.025 \\
\hline$K_{v y l l}(\mathrm{~N} / \mathrm{m})$ & $9.80 \times 10^{5}$ & $K v y 21, K v y 22(\mathrm{~N} / \mathrm{m})$ & $6.370 \times 10^{6}$ & $L v y 3 \quad(\mathrm{~m})$ & 0.7823 \\
\hline$C_{v z l l}(\mathrm{~N} . \mathrm{s} / \mathrm{m})$ & $2.28 \times 10^{4}$ & $C v z 21, C v z 22(\mathrm{~N} . \mathrm{s} / \mathrm{m})$ & $2.610 \times 10^{4}$ & Lvy4 (m) & 0.200 \\
\hline$C_{v y l l}(\mathrm{~N} . \mathrm{s} / \mathrm{m})$ & $3.336 \times 10^{5}$ & $C$ vy $21, C$ vy $22(\mathrm{~N} . \mathrm{s} / \mathrm{m})$ & \multirow[t]{3}{*}{$1.855 \times 10^{5}$} & $L v z 1 \quad$ (m) & 0.885 \\
\hline & & & & $L v z 2 \quad(\mathrm{~m})$ & 0.6300 \\
\hline & & & & $L v z 3 \quad(\mathrm{~m})$ & 1.085 \\
\hline
\end{tabular}

TableA.1.illustrates the adopted properties of Monorail Train [8].

TableA.2. Monorail Natural Frequencies.

\begin{tabular}{|c|c|c|c|}
\hline Mode No. & $\begin{array}{c}\text { Natural Frequency } \\
(\mathrm{rad} / \mathrm{s})\end{array}$ & $\begin{array}{c}\text { Natural frequency } \\
\qquad(\mathrm{Hz})\end{array}$ & $\begin{array}{l}\text { Dominant } \\
\text { Motion }\end{array}$ \\
\hline 1. & 1.349 & 2.12 & Train Body Bounce \\
\hline 2. & 0.889 & 1.99 & Front Bogie Axle hop \\
\hline 3. & 0.849 & 2.18 & Rear Bogie Axle hop \\
\hline 4. & 0.838 & 2.24 & Lateral Translation \\
\hline 5. & 0.806 & 2.42 & Front Bogie Sway \\
\hline 6. & 0.475 & 6.96 & Rear Bogie Sway \\
\hline 7. & 0.457 & 7.52 & Train Body Roll \\
\hline 8. & 0.5436 & 5.31 & Front Bogie Axle Roll \\
\hline 9. & 0.504 & 6.18 & Rear Bogie Axle Roll \\
\hline 10 . & 0.364 & 11.85 & Train Body Pitch \\
\hline 11. & 0.37 & 11.47 & Front Bogie Pitch \\
\hline 12. & 0.414 & 9.16 & Rear Bogie Pitch \\
\hline 13. & 0.32 & 15.33 & Train Body Yaw \\
\hline 14. & 0.334 & 14.07 & Front Bogie Yaw \\
\hline 15. & 0.427 & 8.61 & Rear Bogie Yaw \\
\hline
\end{tabular}


TableA3.Static and Dynamic Properties of Monorail Train [9]

\begin{tabular}{|c|c|c|}
\hline No. & Property & PARAMETER SYMBOL \\
\hline 1. & Mass of body & $m_{v 11}$ \\
\hline 2. & Mass of suspension system & $m_{v 21,} m_{v 22}$ \\
\hline 3. & Spring constant of air suspension(Vertical) & $K_{v 1111}, K_{v 1112}, K_{v 2111}, K_{v 2112}$ \\
\hline 4. & Spring constant of driving wheel & $\begin{array}{l}K_{v 1211}, K_{v 1212}, K_{v 1221}, K_{v 1222} \\
K_{v 2211}, K_{v 2212}, K_{v 2221}, K_{v 2222}\end{array}$ \\
\hline 5. & Spring constant of steering wheel & $\begin{array}{l}K_{v 1311}, K_{v 1312}, K_{v 1321}, K_{v 1322} \\
K_{v 2311}, K_{v 2312}, K_{v 2321}, K_{v 2322}\end{array}$ \\
\hline 6. & Spring constant of stabilizing wheel & $K_{v 1411}, K_{v 1412,} K_{v 2411}, K_{v 2412}$ \\
\hline 7. & Spring constant of air suspension (Lateral) & $K_{v 1511,} K_{v 2511}$ \\
\hline 8. & Damping constant of damper (Vertical) & $C_{v 1111}, C_{v 1112}, C_{v 2111}, C_{v 2112}$ \\
\hline 9. & Damping constant of driving wheel & $\begin{array}{l}C_{v 1211}, C_{v 1212}, C_{v 1221}, C_{v 1222} \\
C_{v 2211}, C_{v 2212}, C_{v 2221}, C_{v 2222}\end{array}$ \\
\hline 10 . & Damping constant of steering wheel & $\begin{array}{l}C_{v 1311}, C_{v 1312}, C_{v 1321}, C_{v 1322} \\
C_{v 2311}, C_{v 2312}, C_{v 2321}, C_{v 2322}\end{array}$ \\
\hline 11. & Damping constant of stabilizing wheel & $C_{v 1411}, C_{v 1412}, C_{v 2411}, C_{v 2412}$ \\
\hline 12. & Damping constant of damper (Lateral) & $C_{v 1511, C_{v 2511}}$ \\
\hline 13. & Vertical and lateral body displacements & $Z_{v 11}, Y_{v 11}$ \\
\hline 14. & Vertical displacements of front and rear suspension system & $Z_{v 21}, Z_{v 22}$ \\
\hline 15. & Lateral displacements of front and rear suspension system & $Y_{v 21}, Y_{v 22}$ \\
\hline 16. & Rolling, pitching and yawing of body & $\theta_{v x 11}, \theta_{v y 11}, \theta_{v z 11}$ \\
\hline 17. & Rolling of front and rear suspension system & $\theta_{v x 21}, \theta_{v x 22}$ \\
\hline 18. & Pitching of front and rear suspension system & $\theta_{v y 21}, \theta_{v y 22}$ \\
\hline 19. & Yawing of front and rear suspension system & $\theta_{v z 21}, \theta_{v z 22}$ \\
\hline 20 & Monorail Body Moment of inertia & $I_{v y 11}, I_{v y 11}$ \\
\hline 21 & Front and Rear Bogies Moment of inertia & $I v x 21, I v x 22, I v y 21, I v y 22, I v z 21, I v z 22$ \\
\hline
\end{tabular}




\section{APPENDIX A.2}

\section{A.2 Motion Equations of 15 DOF Monorail Suspension System}

1- $Z_{v 11}$ : Bouncing

$$
\boldsymbol{m}_{v 11} \ddot{Z}_{v 11}+\sum_{i=1}^{2} \sum_{j=1}^{2} \sum_{n=1}^{2}\left\{K_{v i 1 j n} R_{v i 1 j n}+C_{v i 1 j n} \dot{R}_{v i 1 j n}\right\} \delta_{1 j}=0
$$

2- $Z_{v 21}$ : Axle hop (Front-bogie)

$$
\boldsymbol{m}_{v 21} \ddot{Z}_{v 21}+\sum_{j=1}^{2} \sum_{n=1}^{2}\left\{-K_{v 11 j n} R_{v 11 j n} \delta_{1 j}+K_{v 12 j n} R_{v 12 j n}-C_{v 11 j n} \dot{R}_{v 11 j n}+C_{v 12 j n} \dot{R}_{v 12 j n}\right\}=0
$$

3- $Z_{v 22}$ : Axle hop (Rear-bogie)

$$
\boldsymbol{m}_{v 22} \ddot{Z}_{v 22}+\sum_{j=1}^{2} \sum_{n=1}^{2}\left\{-K_{v 21 j n} \boldsymbol{R}_{v 21 j n} \boldsymbol{\delta}_{1 j}+K_{v 22 j n} \boldsymbol{R}_{v 22 j n}-C_{v 21 j n} \dot{R}_{v 21 j n}+C_{v 22 j n} \dot{R}_{v 22 j n}\right\}=0
$$

4- $\boldsymbol{Y}_{v 11}$ : Lateral translation

$$
\boldsymbol{m}_{v 11} \ddot{y}_{v 11}+\sum_{i=1}^{2}\left\{K_{v i 511} R_{v i 511}+C_{v i 511} \dot{R}_{v i 511}\right\}=0
$$

5- $Y_{v 21}$ : Bogie Sway (Front-bogie)

$$
\boldsymbol{m}_{v 21} \ddot{y}_{v 21}+\sum_{j=1}^{2} \sum_{n=1}^{2}\left\{K_{v 13 j n} R_{v 13 j n}+C_{v 13 j n} \dot{R}_{v 13 j n}+K_{v 14 j n} R_{v 14 j n} \delta_{1 j}+C_{v 14 j n} \dot{R}_{v 14 j n} \delta_{1 j}\right\}-K_{v 1511} R_{v 1511}-C_{v 1511} \dot{R}_{v 1511}=0
$$

6- $Y_{v 22}$ : Bogie Sway (Rear-bogie)

$$
\boldsymbol{m}_{v 22} \ddot{y}_{v 22}+\sum_{j=1}^{2} \sum_{n=1}^{2}\left\{K_{v 23 j n} R_{23 j n}+C_{v 23 j n} \dot{R}_{v 23 j n}+K_{v 24 j n} R_{v 24 j n} \delta_{1 j}+C_{v 24 j n} \dot{R}_{v 24 j n} \delta_{1 j}\right\}-K_{v 2511} R_{v 2511}-C_{v 2511} \dot{R}_{v 2511}=0
$$

7- $\theta_{v x 11}$ : Rolling

$$
I_{v x 11} \ddot{\theta}_{v x 11}+\sum_{i=1}^{2}\left[\sum_{n=1}^{2}\left\{(-1)^{n} L_{v y 2}\left(K_{v i 11 n} R_{v i 11 n}+C_{v i 11 n} \dot{R}_{v i 11 n}\right)\right\}+L_{v z 1}\left(K_{v i 51 n} R_{v i 51 n}+C_{v i 51} \dot{R}_{v i 51 n}\right)-m_{v 11} g \theta_{v x 11} L_{v z 2 i}\right]
$$

$8-\theta_{v x 21}$ : Axle tramp (Front-bogie)

$$
\begin{gathered}
I_{v x 21} \ddot{\theta}_{v x 21}+\sum_{j=1}^{2} \sum_{n=1}^{2}\left\{-(-1)^{n} L_{v y 2}\left(K_{v 11 j n} R_{v 11 j n}+C_{v 11 j n} \dot{R}_{v 11 j n}\right) \delta_{1 j}\right\}+(-1)^{n} L_{v y 4}\left(K_{v 12 j n} R_{v 12 j n}+C_{v 12 j n} \dot{R}_{v 12 j n}\right) \\
\left.+L_{v z 3}\left\{K_{v 14 j n} R_{v 14 j n}+C_{v 14 j n} \dot{R}_{v 14 j n}\right\} \delta_{1 j}\right]=0
\end{gathered}
$$


9- $\theta_{v x 22}$ : Axle tramp (Rear-bogie)

$$
\begin{gathered}
I_{v x 22} \ddot{\theta}_{v x 22}+\sum_{j=1}^{2} \sum_{n=1}^{2}\left[-(-1)^{n} L_{v y 2}\left\{K_{v 21 j n} \boldsymbol{R}_{v 21 j n}+C_{v 21 j n} \dot{\boldsymbol{R}}_{v 21 j n}\right\} \boldsymbol{\delta}_{1 j}+(-1)^{n} \boldsymbol{L}_{v y 4}\left\{\boldsymbol{K}_{v 22 j n} \boldsymbol{R}_{v 22 j n}+C_{v 22 j n} \dot{\boldsymbol{R}}_{212 j n}\right\}\right. \\
\left.+\boldsymbol{L}_{v z 3}\left\{\boldsymbol{K}_{v 24 j n} \boldsymbol{R}_{v 24 j n}+\boldsymbol{C}_{v 24 j n} \dot{\boldsymbol{R}}_{v 24 j n}\right\} \boldsymbol{\delta}_{1 j}\right]=\mathbf{0}
\end{gathered}
$$

10- $\theta_{v y 11}$ : Pitching

$$
I_{v y 11} \ddot{\theta}_{v y 11}+\sum_{i=1}^{2} \sum_{n=1}^{2}\left\{-(-1)^{i}\left(K_{v i 11 n} R_{v i 11 n}+C_{v i 11 n} \dot{R}_{v i 11 n}\right)\right\}=0
$$

11- $\theta_{v y 21}$ : Bogie Windup Front-bogie)

$$
I_{v y 21} \ddot{\theta}_{v y 21}-\sum_{j=1}^{2} \sum_{n=1}^{2}(-1)^{j} L_{v x 3}\left\{K_{v 12 j n} R_{v 12 j n}+C_{v 12 j n} \dot{R}_{v 12 j n}\right\}=0
$$

12- $\theta_{v y 22}$ : Bogie Windup (Rear-bogie)

$$
\boldsymbol{I}_{v y 22} \ddot{\boldsymbol{\theta}}_{v y 22}-\sum_{j=1}^{2} \sum_{n=1}^{2}(-1)^{j} \boldsymbol{L}_{v x 4}\left\{\boldsymbol{K}_{v 22 j n} \boldsymbol{R}_{v 22 j n}+\boldsymbol{C}_{v 22 j n} \dot{\boldsymbol{R}}_{v 22 j n}\right\}=\mathbf{0}
$$

13- ${ }_{v z 11}$ :Yawing

$$
I_{v z 11} \ddot{\theta}_{v z 11}+\sum_{i=1}^{2} \sum_{n=1}^{2}(-1)^{i} L_{v x i}\left\{K_{v i 511} R_{v i 511}+C_{v i 511} \dot{R}_{v i 511}\right\}=0
$$

14- $\theta_{v z 21}$ : Bogie yawing (Front-bogie)

$$
\boldsymbol{I}_{v z 21} \ddot{\theta}_{v 221}+\sum_{j=1}^{2} \sum_{n=1}^{2}\left[(-1)^{j} \boldsymbol{L}_{v x 4}\left\{\boldsymbol{K}_{v 13 j n} \boldsymbol{R}_{v 13 j n}+\boldsymbol{C}_{v 13 j n} \dot{\boldsymbol{R}}_{v 13 j n}\right\}\right]=\mathbf{0}
$$

15- $\theta_{v z 22}$ : Bogie yawing (Rear-bogie)

$$
\boldsymbol{I}_{v z 22} \ddot{\boldsymbol{\theta}}_{v z 22}+\sum_{j=1}^{2} \sum_{n=1}^{2}\left[(-1)^{j} \boldsymbol{L}_{v x 4}\left\{\boldsymbol{K}_{v 23 j n} \boldsymbol{R}_{v 23 j n}+\boldsymbol{C}_{v 23 j n} \dot{\boldsymbol{R}}_{v 23 j n}\right\}\right]=\mathbf{0}
$$




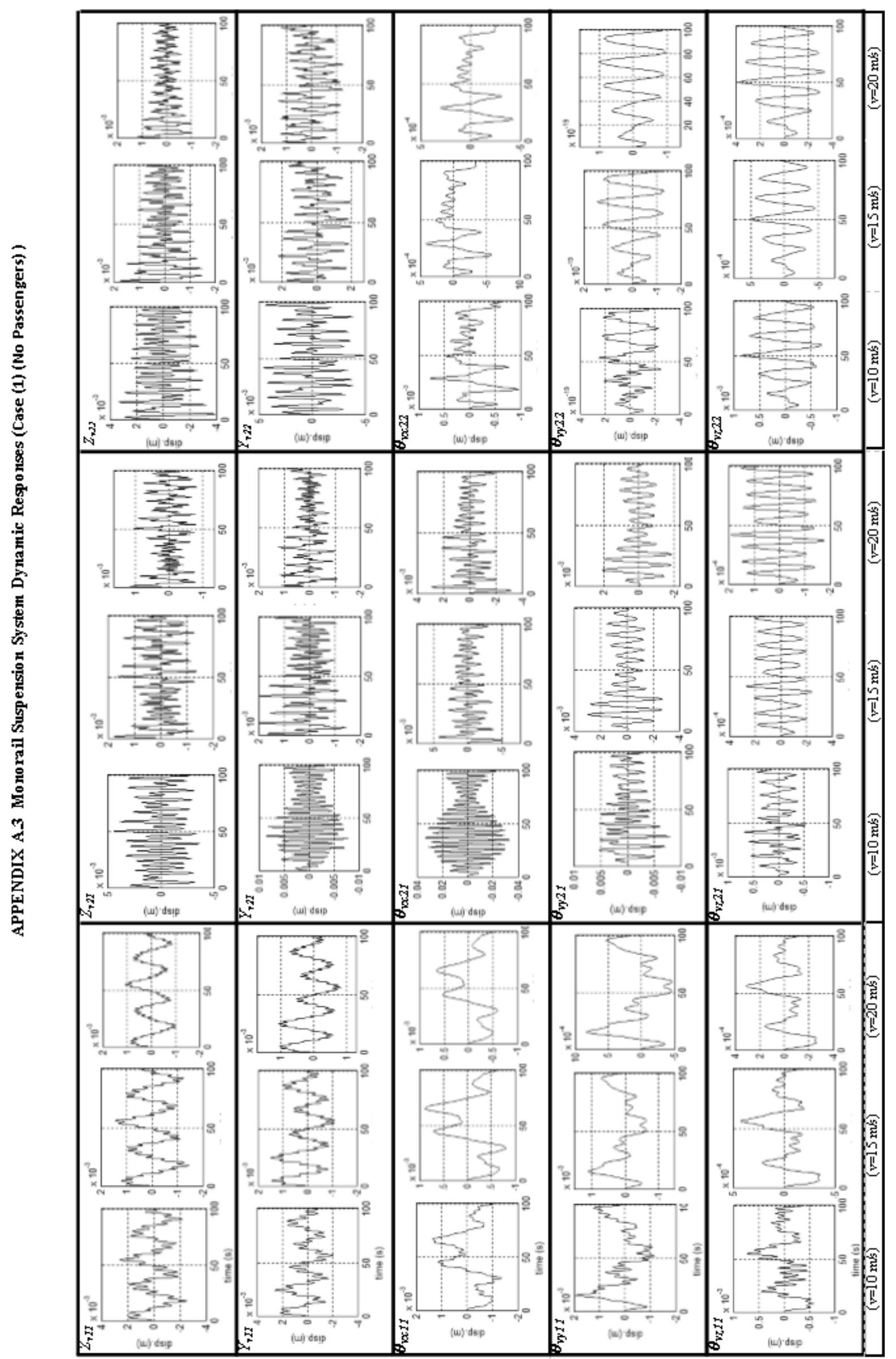




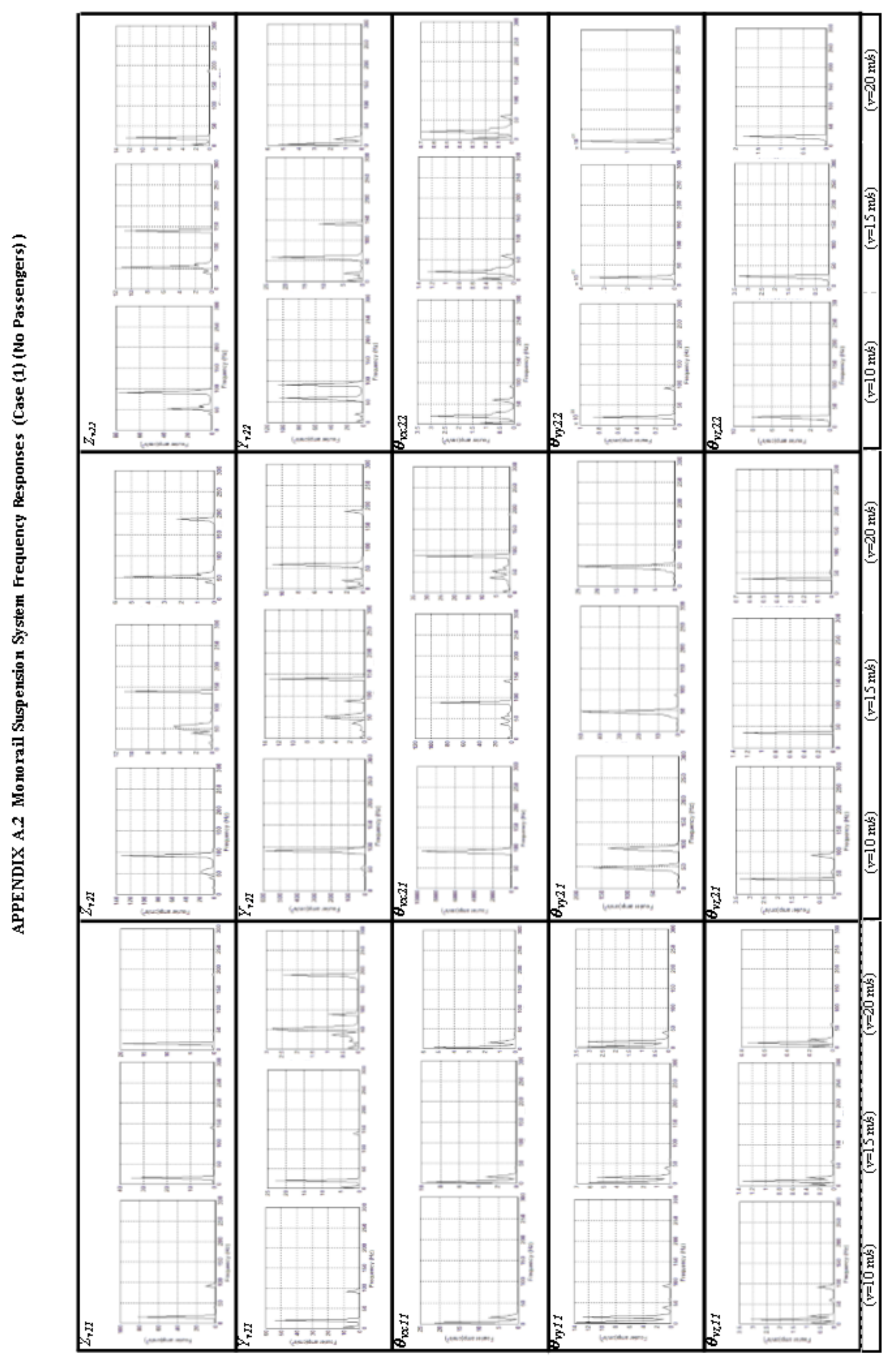

